Review

\title{
Tall Buildings and Elevators: A Review of Recent Technological Advances
}

\author{
Kheir Al-Kodmany \\ Department of Urban Planning and Policy, College of Urban Planning and Public Affairs, University \\ of Illinois at Chicago, Chicago, IL 60607, USA; E-Mail: profkheiralkodmanyuic@gmail.com
}

Academic Editor: Chimay J. Anumba

Received: 26 June 2015 / Accepted: 31 August 2015 / Published: 17 September 2015

\begin{abstract}
Efficient vertical mobility is a critical component of tall building development and construction. This paper investigates recent advances in elevator technology and examines their impact on tall building development. It maps out, organizes, and collates complex and scattered information on multiple aspects of elevator design, and presents them in an accessible and non-technical discourse. Importantly, the paper contextualizes recent technological innovations by examining their implementations in recent major projects including One World Trade Center in New York; Shanghai Tower in Shanghai; Burj Khalifa in Dubai; Kingdom Tower in Jeddah, Saudi Arabia; and the green retrofit project of the Empire State Building in New York. Further, the paper discusses future vertical transportation models including a vertical subway concept, a space lift, and electromagnetic levitation technology. As these new technological advancements in elevator design empower architects to create new forms and shapes of large-scale, mixed-use developments, this paper concludes by highlighting the need for interdisciplinary research in incorporating elevators in skyscrapers.
\end{abstract}

Keywords: energy saving; efficiency; speed; long distances; comfort; safety; security

\section{Introduction}

When people think about the development of cities, rarely do they contemplate the critical role of vertical transportation. Consider, however, that each day, more than 7 billion elevator journeys are taken in tall buildings all over the world [1,2]. Efficient vertical transportation has the ability to limit or expand 
our ability to build taller and taller skyscrapers, and recent innovations in elevator design promise to significantly reduce energy consumption.

Antony Wood, 2014, a Professor of Architecture at the Illinois Institute of Technology (IIT) and the Executive Director of the Council On Tall Buildings and Urban Habitats (CTBUH), explains that advances in elevators over past 20 years are probably the greatest advances we have seen in tall buildings [1]. Indeed, the race to build ever taller skyscrapers has sparked fierce competition among lift manufacturers to build faster, more efficient, safer, more comfortable and more economical elevators. For example, elevators in the Kingdom Tower in Jeddah, Saudi Arabia, under construction, will reach a height record of 660 m (2165 feet); and elevators in CTF Finance Center in Guangzhou, China, under construction, will travel with a speed record of $20 \mathrm{~m} / \mathrm{s}$ (66 feet per second).

Daniel Levinson Wilk, a Professor of History at the Fashion Institute of Technology in New York and a board member of the Elevator Museum in Queens, explains in an article, 2014, titled "How the Elevator Transformed America" that the elevator is responsible for shaping modern life in ways that most people simply don't appreciate and that he would like people to be more conscious of the elevators in their lives [3]. Professor Wilk is particularly "disappointed with his fellow academics-people who are supposed to be studying how the world works-for failing to consider just how much elevators matter" [3].

Similarly, Andreas Bernard's research shows [4] how elevators have been responsible for reshaping modern cities by concentrating large masses of people and activities in smaller areas, creating vibrant communities. Spatially speaking, the elevator's role has been no less profound than that of the automobile in transforming modern cities. While cars have facilitated horizontal spread of cities and regions, encouraging sprawl and suburbia, elevators have enabled concentrating a large number of people and human activities in a smaller footprint. New advances in elevator technologies are likely to reshape cities further by enabling even taller buildings [2,3].

In addition to highlighting the importance of elevators in the development of our cities, this paper aims to educate about the intersection of green technologies with energy efficient elevators. New innovations are leading to the introduction of energy efficient elevators that not only consume less energy, but also produce clean energy. In this regard, the paper advocates for investment in innovative research and development of "green” elevators. "Green” has become an emerging and dominant design philosophy. With so many building products being marketed with a "green” angle, this paper provides useful information to help in making "green" choices when it comes to incorporating elevators in skyscrapers [5-9]. Architects and architectural students may particularly find this aspect of the paper useful since it contains essential knowledge for incorporating elevators in tall buildings.

Third, this paper discusses the need for revisions to local building codes to allow and encourage adoption of "green" elevators. Restrictive building codes in some countries, including the United States, are often a barrier to employing innovative, emerging, elevator technologies. Governments should consider financial incentives, perhaps in the form of tax credits, for the incorporation of green elevators into future skyscrapers and the retrofitting of green elevators into older buildings. Authorities should also encourage projects to pursue an efficiency-rating system such as LEED, BREAM, and ENERGY STAR [10,11].

To accomplish these goals, this research delves into the recent technological innovations of global leaders of elevator manufacturers (e.g., KONE, Helsinki, Finland; Otis, Farmington, CT, USA; Mitsubishi, 
Tokyo, Japan; Hitachi, Tokyo, Japan; and ThyssenKrupp, Essen, Germany). These companies are producing and implementing premium elevators that enjoy improved controls, hardware, and other systems that not only use less energy but are also much more compact, efficient, and even generate electricity that a building can use. This study also builds on the work of many scholars who have been active in elevator design and technology research [12-18].

The paper follows a simple structure. First, it describes recent technological advancements in elevator design. Next, it furnishes five detailed case studies that illustrate incorporating state-of-the-art technologies in major skyscraper projects around the world including: One World Trade Center in New York; Shanghai Tower in Shanghai; Burj Khalifa in Dubai; Kingdom Tower in Jeddah, Saudi Arabia; and the green retrofit project of the Empire State Building in New York. Then, the paper discusses technologies that focus on the passenger experience, including speed, comfort, security, and entertainment. Finally, it addresses future research and development on elevator design.

\section{Recent Technological Developments}

Much of the "green" agenda focuses on reducing energy consumption. Buildings consume about $40 \%$ of the world's energy, and elevators account for $2 \%-10 \%$ of a building's energy consumption. During peak usage hours, elevators may utilize up to $40 \%$ of the building's energy [19]. Glen Pederick, 2014, explains that everyday there are more than 7 billion elevator journeys taken in buildings all over the world; and as such, energy-saving elevators will reduce energy consumption significantly [20]. Fortunately, new technologies and best practices involving motors, regeneration converters, control software, optimization of counterweights and cabin lighting can yield significant savings [20,21]. New elevators provide efficiency gains of about 30-40 percent than buildings with older lifts [14]. Researcher Patrick Bass writes of recent examples of ThyssenKrupp technologies that provide energy savings of about $27 \%$ and space saving of about $30 \%$ [22]. Research on energy efficiency conducted by De Almeida and colleagues has indicated that "considerable technical efficiency potentials exist for elevators (more than 60\%)" [23]. They write "By improving the energy efficiency in existing and new equipment, elevators and escalators can contribute to current energy and climate targets in Europe.” Quantitative studies on energy consumption of newer and older elevator technologies are now being conducted to assess the value of the new technologies. In this regards, ISO 25745-2:2015 standards are used to help to estimate energy consumption. These standards provide measured values and calculations on an annual basis for different types of elevators and present the data according to different energy classification systems for new, existing, and modernized elevators.

However, research by De Almeida et al. explains that lack of awareness of "green" elevator technologies has impeded the full implementation of these technologies. This paper serves to respond to this gap and educate architects and developers on how to harness the power of these new technologies. For simplicity, new elevator technologies are discussed within two categories: energy-efficient hardware (e.g., AC power, machine-room-less technology, regenerative drives, elevator ropes, TWIN systems, double deck elevators, and LED lighting); and energy-efficient software (e.g., destination dispatching systems, people flow solutions, and standby solutions). Other technologies related to elevators are discussed in the subsequent section. In order to provide development continuity, the discussion starts by 
briefly mentioning earlier energy-efficient innovations and then moves quickly to the most recent ones $[8,12,23]$.

\subsection{Energy-Efficient Hardware}

\subsubsection{AC and DC Motors}

One of the significant advances in elevator technology has been from the replacement of conventional brushed DC (direct current) motors with more efficient AC (alternating current) motors. Before the 1990s, elevator systems relied on DC motors because it was easier to control elevator acceleration, deceleration, and stopping with this form of power. As a result, AC power typically was restricted to freight elevators, where comfort and speed are not as critical as in passenger elevators. By the late 1990s, however, more elevators had moved to AC machines because motor controller technology had advanced enough so that it could regulate AC power, enabling smooth stopping, acceleration, and deceleration $[9,12,24]$.

\subsubsection{Geared and Gearless Motors}

High-rise buildings typically employ geared or gearless traction elevators capable of high or variable speed operation. In geared machines, the electric traction motor drives a reduction gearbox whose output turns a sheave over which the rope passes between the car and the counterweights. In contrast, in gearless elevators, the drive sheave is directly connected to the motor, thereby eliminating gear-train energy losses. Therefore, a major advantage of gearless motors is they save about 25 percent more energy than geared motors. Gearless motors also run faster and enjoy greater longevity because they feature higher torque and run at lower RPMs. The major disadvantage of gearless elevators is cost; materials, installation, and maintenance are generally more expensive than geared elevators. In spite of the cost, more elevators today use AC, gearless motor machines because they are more efficient and last longer [12,25].

\subsubsection{Machine-Room-Less (MRL) Technology}

Introduced in the mid-1990s, machine-room-less (MRL) technology was one of the biggest advances in elevator design since they went electric a century before. Manufacturers redesigned the motors and all other equipment normally housed in a machine room to fit into the hoistway, eliminating the need to build a machine room. Earlier, elevator equipment was so massive that a dedicated machine room (about 8 feet tall or greater) was required, usually placed above the hoistway atop a building's roof. The machine room was costly because it needed to support heavy machinery (Figure 1). Today, MRL elevators are increasingly common [14,26]. The MRL system becomes even more energy efficient when it is combined with regenerative drives $[14,26]$. 


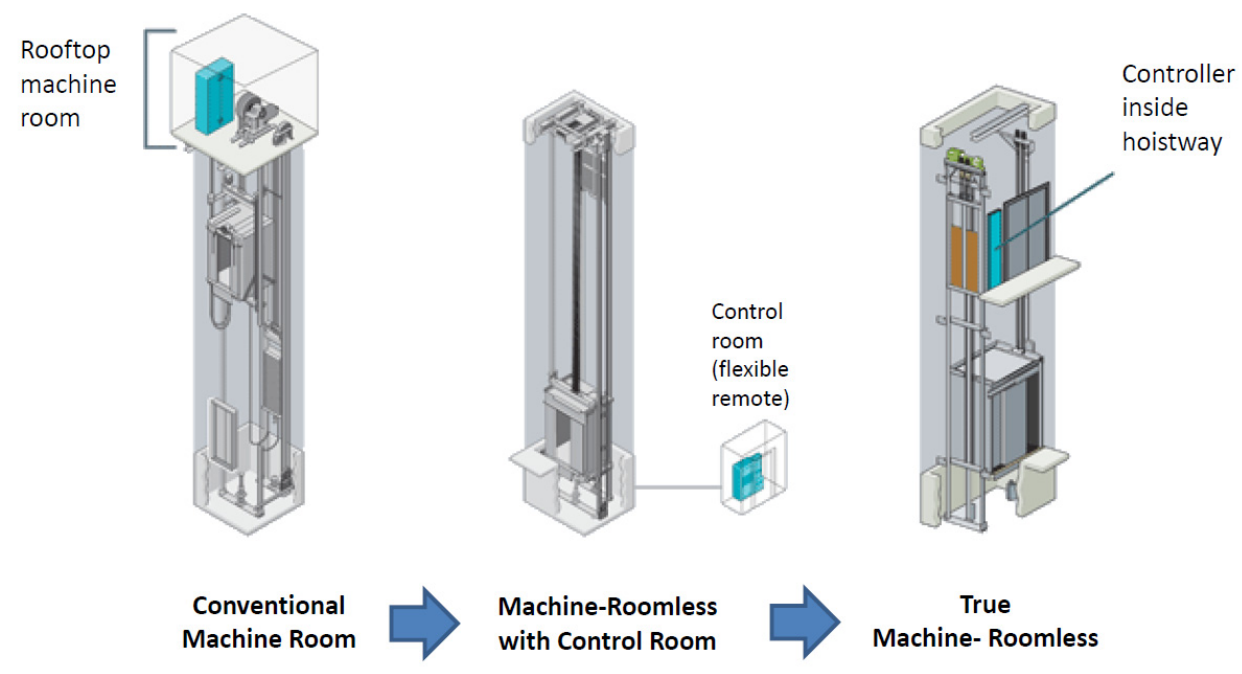

Figure 1. Gearless Machine-Roomless Revolution. Note space saving factor as technology advances. This increases usable spaces, which is crucially important in skyscrapers. (Source: http://www.otisworldwide.com).

\subsubsection{Regenerative Drives}

Regenerative drives are another remarkable advancement in energy-efficient elevator technology, providing the ability to recycle energy rather than waste it as heat. They work by capturing and converting the energy used from braking to maintain the elevators speed. More specifically, traction elevators use a counterweight to balance the weight of the elevator car and passengers. The counterweight is sized in an optimal way, approximately to a car loaded to $40 \%-50 \%$ of capacity. Hypothetically, if the counterweight is too heavy or too light, then the elevator will overwork the motor and the braking system. Instead, a middle weight is effective at leveling energy use in both up and down directions. When the elevator car is loaded less or more than the 50 percent capacity (traveling up cars are light, or traveling down cars are heavy) the elevator applies brakes to maintain their rated speed. Braking is provided by allowing the AC motor to operate as a generator, converting mechanical energy to electrical energy which is dissipated as heat by special heat resistors. The regenerative drive captures that energy and channels it back to the building or the city power grid $[15,16]$.

Hughes [27], explains that the regenerative drive can harness and save energy in multiple ways including (Figure 2):

- When the elevator slows down, it applies brakes and energy is created. In a conventional elevator system, that energy is dissipated as heat through a heat resister. The regenerative drive harnesses that energy.

- Whenever an empty or lightly loaded elevator goes up, the elevator applies brakes to maintain the rated speed. As is the case of slowing down, that energy is usually lost but the regenerative drive harnesses it. Further, when an empty or a lightly loaded elevator goes up, the motor spins but the elevator's counterweight does most of the work. The regenerative drive harnesses that spinning energy by transforming mechanical power into electrical power.

- When a heavy elevator goes down, it applies brakes to maintain the desired speed. In a conventional system, the energy created by the braking system is lost. The regenerative drive harnesses that 
energy. Further, when a heavy elevator goes down, the motor spins but gravity does most of the work. The regenerative drive again harnesses that spinning energy by transforming mechanical power into electrical power.

- There is an additional energy savings that results from eliminating the need to cool equipment that gets exposed to excess heat generated by conventional motors.

- By design, regenerative drives use less energy than non-regenerative drives because they are much smaller, compact, and more efficient.

- When a heavily-loaded elevator goes down, it applies brakes to maintain the desired speed. In a conventional system, the energy created by the braking system is lost. The regenerative drive harnesses that energy. Further, when a heavily-loaded elevator goes down, the motor spins but gravity does most of the work. The regenerative drive again harnesses that spinning energy by transforming mechanical power into electrical power.

- When an empty or lightly loaded elevator goes up, the elevator applies brakes to maintain the rated speed. That energy is lost in conventional elevators but the regenerative drive harnesses it. Further, when an empty or a lightly loaded elevator goes up, the motor spins but the elevator's counterweight does most of the work. The regenerative drive harnesses that spinning energy by transforming mechanical power into electrical power. (Source: http://www.otisworldwide.com).
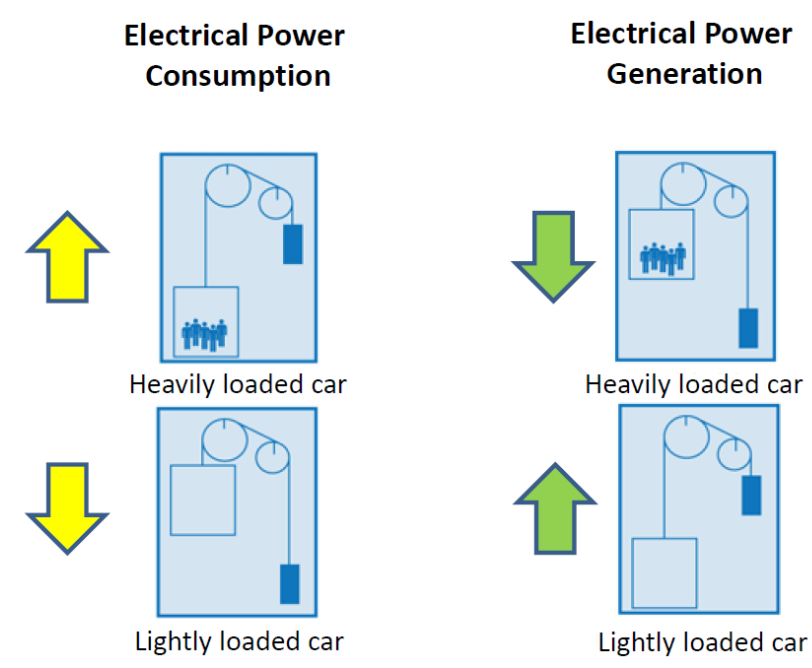

Figure 2. The regenerative drive system.

Over time these small amounts of harnessed and saved power on a daily basis add up to significant energy savings. Generally, a regenerative drive can reduce energy consumption between $20 \%$ and $40 \%$. The ultimate amount of energy savings depends on several variables including: length of trips, frequency and pattern of use, and age of equipment [28]. Overall, the longer the traveled distances and the greater the number of trips result in the greater generated energy (Figure 3). 


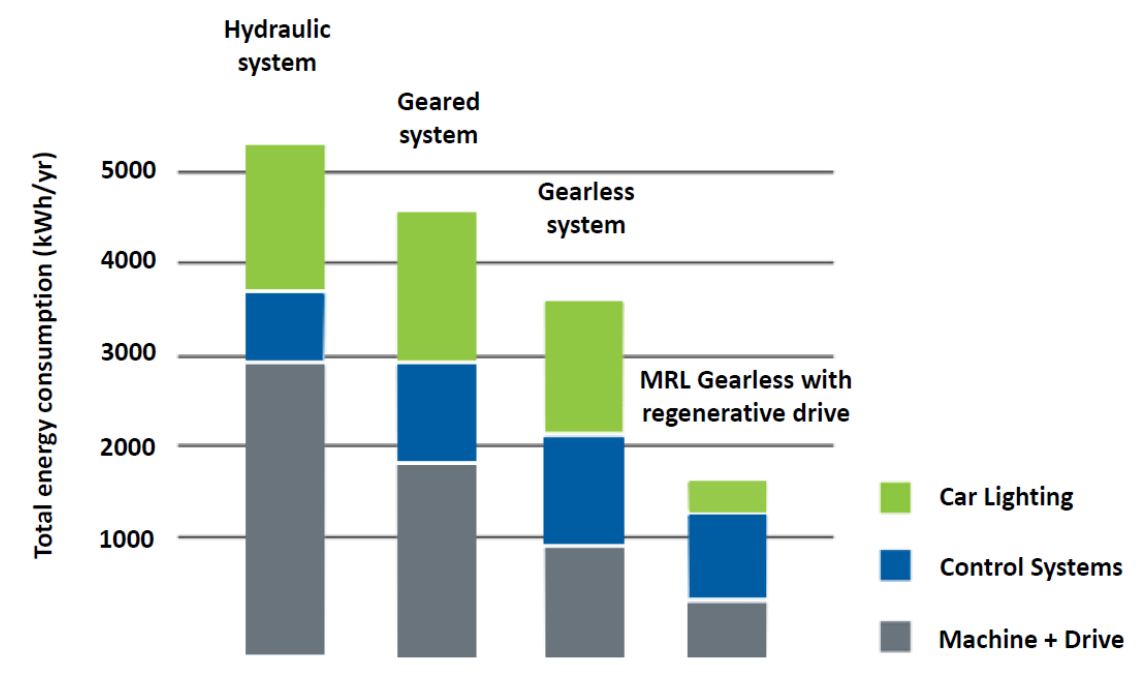

Figure 3. A comparison of energy consumptions among different elevator systems. (Source: http://www.otisworldwide.com).

\subsubsection{Elevator Rope}

The elevator rope is an essential component of traction elevators because it connects the elevator engine with the cab, sheaves, and counterweight. Conventionally, ropes are made of steel, which is strong enough to hold cabins. However, in supertall and megatall buildings, as these ropes get longer, they get extremely heavy - the rope weight increases exponentially with height. In very tall buildings, ropes may stretch for too long, adding dozens of tons of additional weight that can result in the rope breaking or snapping. In very tall buildings, almost $70 \%$ of the elevator's weight is attributed to the cable itself, and when the rope gets too long it cannot support its own weight [29].

Johannes de Jong, Head of Technology at KONE, 2014, explains that the total rope's weight for an elevator with a rated load of 2000 kilograms at a travel distance of $500 \mathrm{~m}$ can be about 27,000 kg. This weight needs to be accelerated and decelerated, and starting currents and energy consumption grows fast with the increase in height ([29], p. 822). De Jong further explains that when a 50-70 ton rope moves just 21 passengers, the long-term financial and ecological values of these systems are questionable. Another significant problem with very long cables is that during strong winds, they over sway and vibrate like guitar strings." Consequently, long cables cause damage to the shaft and to themselves. For example, in the former World Trade Center Twin Towers, the elevators' cables swung back and forth in the building, and over the decades, their movements resulted in wearing deep holes in the shaft walls $[17,30]$.

In response to these problems, elevator companies have been working on improving cable capabilities. For example, Schindler has invented the aramid fiber rope, which is stronger and lighter than the conventional steel rope. Similarly, Otis has designed compact Gen2 lifts that replace the steel rope with a band of ultra-thin cables encapsulated in a polyurethane sheath. According to Otis, the new belt system is stronger and enjoys greater longevity than their original steel cables (Figure 4). In the same manner, Mitsubishi has manufactured a stronger, denser rope that incorporates concentric-layered steel wire. These stronger and lighter ropes require less energy to move and transport elevator cabs, leading to significant power savings. 


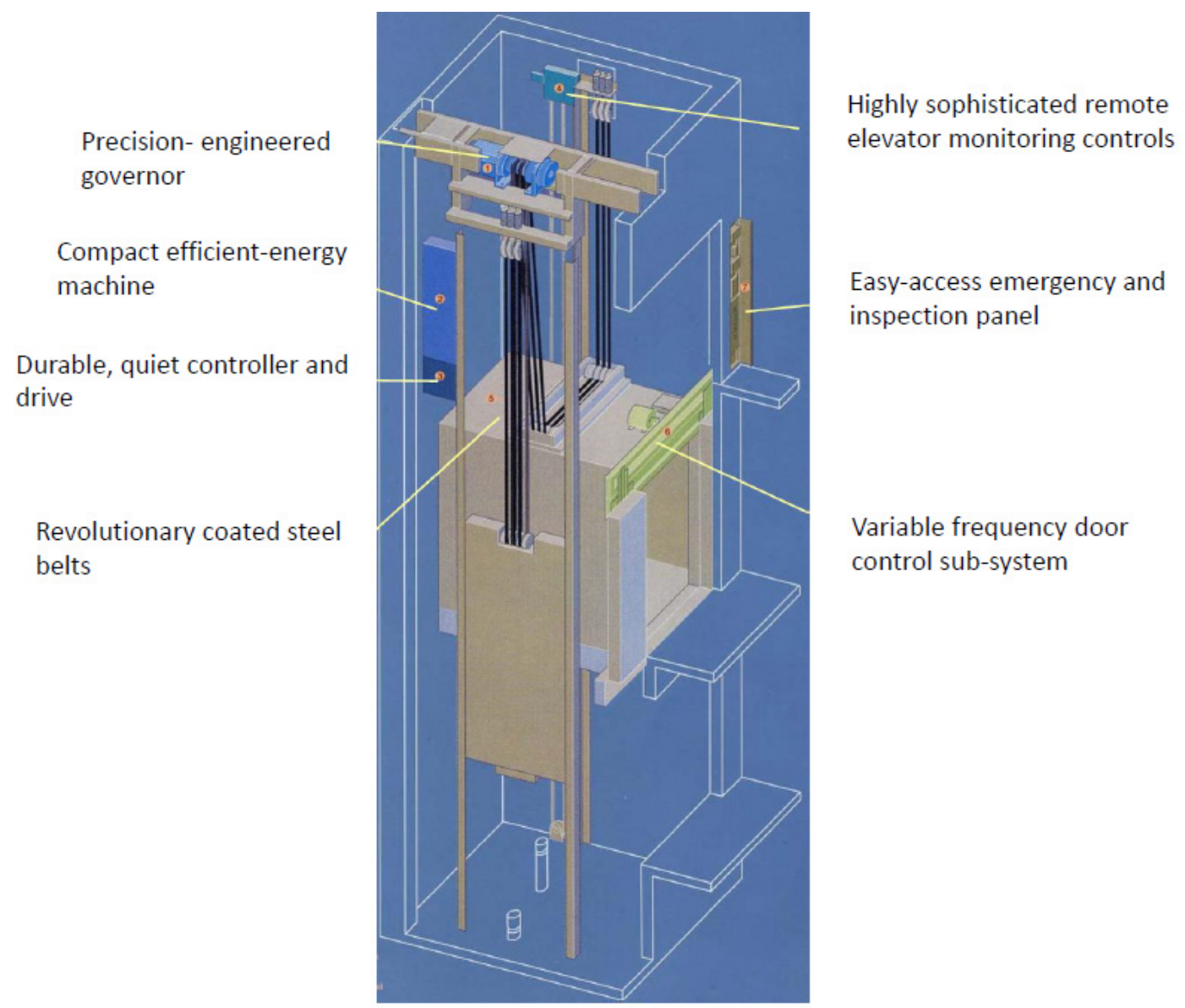

Figure 4. Diagram of OTIS GeN2 Lift. (Source: http://www.otisworldwide.com).

However, the most significant breakthrough came recently from KONE. The "UltraRope" is comprised of a carbon-fiber core and a unique high-friction coating, making it extremely light and enabling cars to travel up to $1000 \mathrm{~m}$ (3280 feet). This is double the current maximum distance of $500 \mathrm{~m}$ (1640 feet) that cars can travel. Johannes de Jong explains “At a travel of $500 \mathrm{~m}$ the weight of the UltraRope is only 10\% of the weight of steel ropes. This means that rope weight of a 2000-kilogram elevator traveling $500 \mathrm{~m}$ is only about 2500 kilograms with UltraRope, compared with 27000 kilograms with ultra-high strength steel ropes. The 90\% reduction in rope mass also reduces the total moving masses by no less than 45\%” ([29], p. 822-823). Further, in the case of maintenance and repair, the lighter UltraRope would require much less time for replacement than regular ropes, reducing downtime considerably. This large decrease in weight also reduces the energy needed in the acceleration and deceleration phases, resulting in about 15\% energy reduction. According to Antony Wood, in summary, once the rope weight is reduced, the whole elevator system becomes more efficient [1].

This technological advancement is, referred to by Johannes de Jong as "the biggest change in elevators since 1853." These carbon-fiber ropes are exciting to architects and developers as they may pave the path for a new generation of ever-taller buildings, even making Frank Lloyd Wright's one-mile tower (Illinois Tower) proposal technologically quite feasible [30-32]. This also implies that the $828 \mathrm{~m}$ (2728 feet) Burj Khalifa in Dubai, in which the longest elevator travels a distance of $504 \mathrm{~m}$ (1654 feet), will not remain the world's tallest building for very long. Antony Wood explains: 
"This is finally a breakthrough on one of the "holy grail" limiting factors of tall buildings-that is, the height to which a single elevator could operate before the weight of the steel rope becomes unsupportable over that height-so it is not an exaggeration to say that this is revolutionary. However, it is not just the enablement of greater height that is beneficial-the greater energy and material efficiencies are equally important” [32].

According to KONE, the UltraRope makes sense in buildings $200 \mathrm{~m}$ or taller. The UltraRope will be implemented in the one-kilometer Kingdom Tower in Jeddah, Saudi Arabia, under construction (See Case Studies Section).

\subsubsection{The TWIN System}

Germany-head quartered ThyssenKrupp, jointly with Eros Elevators \& Escalators, has developed a TWIN-system for high-rise buildings. The advantage of the TWIN is that two cabs run independently in a single shaft. The system keeps a safe distance between the two elevators (upper and lower cabins) that are running on top of each other [33,34]. The TWIN system basically provides savings in space as it cuts the number of shafts needed by one-third, compared to conventional elevators. Glen Pederick explains that the overall floor area savings from installing two less elevator shafts and a smaller lobby on each floor of a 31-story building is more than $830 \mathrm{~m}^{2}$, which is equivalent to an area of 20 hotel rooms [35].

In addition to freeing useful space, the TWIN system reduces required building materials for shafts, and hence reduces costs. There is also one control machine for both elevators in the same shaft, leading to additional savings on space and energy. Through a computerized system, it also optimizes the travel of both cabins in assigning the most efficient destinations for passengers, providing efficient service that minimizes wait time and provides fewer stops and empty trips. This leads to additional energy savings. TWIN cars can travel in the shaft up to $7 \mathrm{~m} / \mathrm{s}$ (23 feet/s) and travel down about $4 \mathrm{~m} / \mathrm{s}$ (13 feet/s). When the TWIN system is applied, it is often mixed with non-TWIN lifts. The latter serves passengers who want to travel directly, for example, from the lowest floor to the top floor and vice versa [34].

\subsubsection{Double Deck Elevators}

Double Deck elevators are two cabs tall, where one cab serves even-numbered floors and the other serves odd-numbered floors, resulting in reducing the total number of needed elevators. Johannes de Jong explains that " a 52-story office building, which earlier would have needed 24 single deck cars in three zones, can now be designed using only two zones with a total of only 13 Double Decker elevators, reducing the required core by no less than 11 hoistways” ([28], p.1). Double Deck elevators can reduce a building's overall energy usage by reducing the number of stops and even the total number of elevators required when used with destination dispatch controls. As skyscrapers are getting higher, reducing the number of needed elevators becomes more important because they eat up valuable interior space on every floor [35]. This is more critical in upper floors where floor size gets smaller. In general, space-saving elevator design is important because in high-rises elevators occupy more space than any other services.

Above 60 floors, arrangements of Double Deck elevators and sky lobbies could be useful. Also, Double Deck elevators are most useful for shuttle applications in very tall buildings. However, the Double Deck elevators also suffer from some operational challenges. For example, for local service, 
Double Deck elevators must load and unload two decks simultaneously. In addition, Double Deck elevators require stairs or escalators in the main lobby so that passengers can move between the lower and upper level lobbies to get to their destination floor [36]. Consequently, Double Deck elevators became less popular because of passengers' dissatisfaction with having to transfer levels at the main lobby and due to non-coincident stops. In response, Klan et al. [36], de Jong and Pederick indicate that when Double Deck elevators are combined with Destination Dispatching Systems (See Section 2.2.1), these problems are mitigated substantially. Knowing each passenger's destination enables the system to allocate passengers to elevator decks and cars strategically, allowing passengers to catch their elevator service from either the upper or the lower lobby, improving the overall performance of the service and reducing non-coincident stops [35,37].

\subsubsection{LED Lighting}

Robert Boog explains that energy efficient LED cab lights within an elevator car and their adjustment to movement detectors are one of the main contributors toward efficient power consumption in a building. LEDs (light-emitting diodes) save substantial energy for they require less power than incandescent, halogen, and fluorescent lamps. LED also emits less heat, resulting in less energy needed to cool the cab. LED lighting is currently utilized in many new buildings. Additionally, building owners are replacing traditional elevator lighting systems with LED lighting [38].

\subsection{Energy-Efficient Software}

New elevator control software allows for the conducting of elevator traffic studies, which inform how an elevator's cycle affects its energy use. By observing and studying the irregular nature of elevator operation, number of floors traveled, periods of peak load, and low-load and empty trips, researchers can create energy consumption models that help to develop efficient control strategies and make recommendations for best management.

\subsubsection{Destination Dispatching Systems}

In a conventional call system, the users push up and down buttons, and elevators answer the call. This system works fine in buildings that have low "vertical ridership" and do not experience "rush hour" traffic. In heavy traffic, lots of buttons are pushed that will result in lots of elevator stops, increasing travel and wait time. Johannes de Jong explains that in a high speed elevator, say with a speed of $6 \mathrm{~m}$ per second, each stop may require as much as 10-13 s [29].

To address this problem, elevator designers have invented the Destination Dispatching System (DDS). It was first introduced in the 1990s following the surge of increased microprocessor capacity during the 1980s. A DDS is an optimization technique used for multi-elevator installations, which groups passengers for the same destinations into the same elevators. In real-time, the system analyzes input data from passengers and efficiently groups their destinations, resulting in decreasing the number of stops in every elevator's trip. Upon entering a destination by using keypads or touch screens on the Destination Operation Panel (DOP), usually placed strategically in the lobby, the system quickly signals and directs each passenger to the assigned elevator to board (Figure 5). 

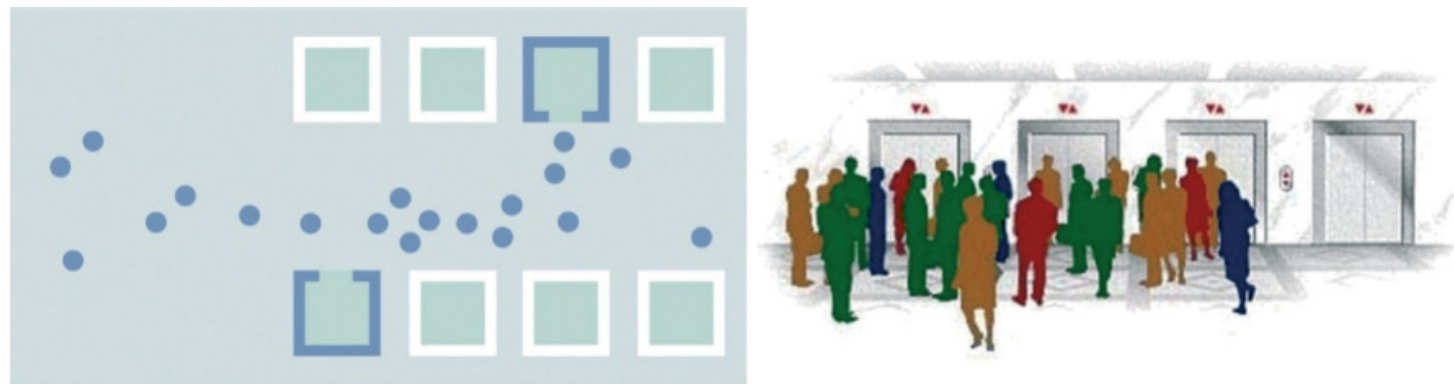

Conventional dispatching system
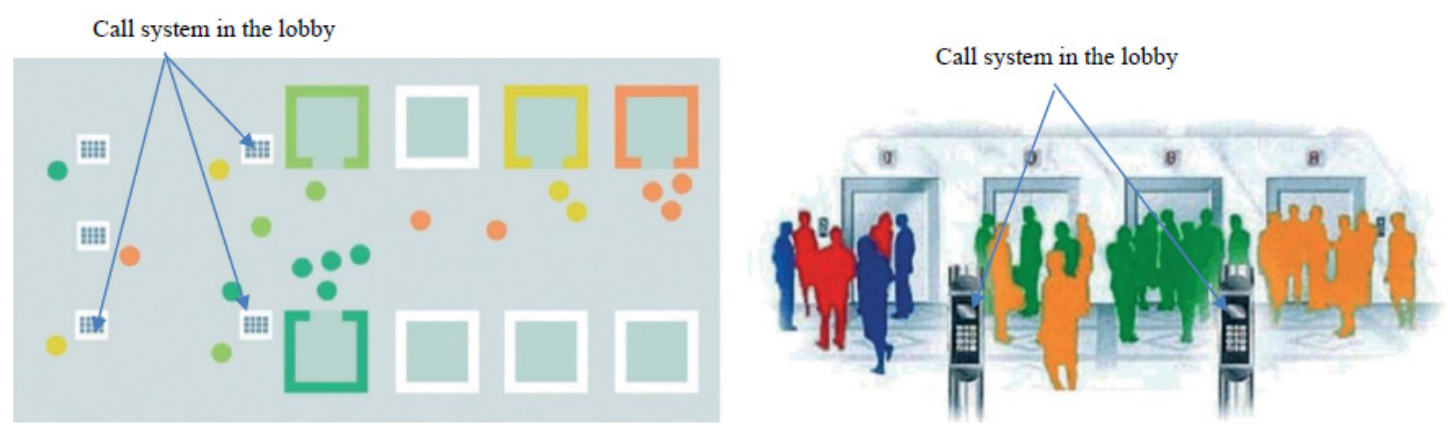

Destination dispatching system

Figure 5. Conventional (top) versus destination dispatching system (bottom). In conventional systems, passengers press an up-or-down call button and wait. Then the crowd board the first arriving car, jostle to select their destination and stop at every floor selected. With the latter system, passengers input their destinations prior to entering the car using keypads or touch-screens strategically placed in the lobby. The system instantly directs each passenger to a car specifically assigned to his or her requested floor. Once in the elevator car, it automatically takes the passenger to the destination floor. (Source: http://www.ThyssenKrupp.com).

\section{DDS Benefits}

James Fortune explains that the DDS provides important benefits including decreasing energy consumption, reducing waiting time, and minimizing crowding and congestion in the building lobbies and hallways. DDS' manufacturers claim that the average traveling time can be reduced by about 30 percent. Katherine Rosman indicates that the average wait time for the elevator in a typical 16-floor building with a dispatch system is $13 \mathrm{~s}$, while the average wait time for the elevator in the same building with a conventional system is $138 \mathrm{~s}$ [37].

In addition to saving time, the system eases pedestrian traffic flow since each passenger heads directly to a specific elevator, eliminating the need to rush to every arriving elevator, a common behavior exhibited by passengers. The system also improves accessibility, as a mobility-impaired passenger can move to his or her designated car in advance. The DDS is mostly appreciated during elevators' "rush hours", usually experienced in the morning and lunchtime [18]. Due to increased efficiencies in handling a large number of people, DDS reduces the required number of elevators. It also decreases wear-and-tear factor because elevators make fewer stops [39,40]. 


\section{DDS Implementations}

The way of using the DDS could lead to different levels of energy saving. For example, if the system has a passenger wait, say, an extra $15 \mathrm{~s}$ to get in an elevator that is already in transit, rather than immediately sending another elevator, it should save energy without inordinately affecting passenger service. Some systems also reduce elevator speed during low traffic times by about ten percent. That also will save energy without substantially affecting the service [39]. Another management strategy is related to switching the DDS mode from single to multiple destinations for optimizing performance in rush hours. That is, the DDS can assign a single elevator that travels to a range of destinations such as floor seven through floor nine, while assigning another elevator to destinations that range from floor ten through floor twelve, for example.

The DDS can be implemented as "full configuration" or "hybrid configuration”. In the "full configuration" scenario, destination hall panels are installed on all floors. In contrast, in the "hybrid configuration” case, the destination hall panels are installed only on the busiest floors (mainly the ground or lobby floor), while the other floors have conventional up and down call buttons. This is particularly beneficial to improve traffic flow leaving from the busiest floors, and is especially useful in buildings with heavy up peak traffic [39].

One problem with dispatching systems is that they do not differentiate a group of passengers from a single passenger. This could potentially lead to an elevator stopping to pick up more passengers than the elevator actually has capacity for, creating delays for other passengers. This situation is handled by two solutions: providing a load vane sensor on the elevator or supplying a group function button on the keypad. The load vane tells the elevator controller that there is a high load in car and doesn't stop at other floors until the load is low enough to pick up more passengers. The group function button asks for how many passengers are going to a floor, and then the system sends the correct number of elevators to that floor.

\section{DDS and Security}

In today's world, ensuring security in skyscrapers is exceedingly important. In this regard, the DDS can function as a secondary ring of security for buildings. For example, the DDS can help restrict access to certain floors by employing electronic devices that carry personal information. When scanned upon entering a building, the keycard integrates with the elevator dispatch system and can be set to call elevators that go directly to the floor for which the cardholder has clearance. In the same manner, if a visitor or tenant enters a location that requires a security clearance, the kiosk will prompt the user for security approval. Identifying devices come in many forms including keycards, RFID cards, infrared beams, key fobs, badges, PIN codes, key tags, and even watches. The card reading system also solve the problem of having one person press the elevator button multiple times, making the system think that there are multiple people waiting for the elevator; and hence, it may allocate an empty car to serve a single person [39].

DDS and Other Applications

Some systems use the card reader to alert the elevator to special needs. For example, a passenger who has trouble walking could be assigned to a closer elevator, or the doors could be held open longer. 
If someone uses a wheelchair, fewer people could be assigned to the elevator to be sure that there is enough space. If someone is blind, a recording could speak the elevator letter or number. An elevator system could even be integrated into a building's heating and cooling system so the temperature could be adjusted when people arrive in the morning and leave in the evening. DDS can also play a role when construction or renovation work is being performed. Facility executives could set keycards to access only the floors under construction for any long-term contractors, while locking out access to floors of the rest of the building [26].

\subsubsection{People Flow Solutions}

Similar to the DDS, People Flow Solutions are designed to smooth people flow and manage demand on elevators but mainly in extreme cases. This is illustrated in the case of the Abraj Al Bait Hotel Complex in Makkah, Saudi Arabia. The complex comprises seven towers including the tallest, the Clock Royal Tower that reaches a height of $601 \mathrm{~m}$ (1972 feet) with 120 floors, and a 15-story podium. It is situated in close proximity to the Masjid Al Haram, the holiest mosque in the Islamic faith. The hotel's visitors travel to the Masjid Al Haram five times a day to conduct congregational prayers. The daunting task is to enable 75,000 people residing in the building complex to join the five daily prayers in the Masjid Al Harm within 30 min or less, and then bring them back to the hotel in a similar period of time. This required a careful study to understand "people flow" and to provide optimal solutions. The study recommended the implementation of over 180 elevators and more than 100 escalators in the hotel complex; 94 elevators and 16 escalators in the Makkah Clock Royal Tower. The elevators include large shuttles that can hold 54 passengers each and take visitors up to the 15th level, one of the sky lobbies of the tower. KONE has implemented a special group control software with artificial intelligence capabilities to learn and track passengers' traffic patterns in order to optimize people flow solution [41].

\subsubsection{Standby Solutions}

Standby solutions power down the elevator's equipment when it is not in use, providing substantial energy savings, especially in buildings with periods of low elevator usage. In-cab sensors and software automatically switch to a "sleep mode," turning off lights, fans, music, and video screens when unoccupied. Energy savings from standby solutions could vary between $25 \%$ and $80 \%$ of the overall consumption of the elevator, depending on multiple variables including the employed control system, lighting type, floor displays and operating consoles in each floor and inside the elevator cabin. For example, the lighting feature would greatly factor in the saving formula. Lighting inside the elevator cabin can be switched off $40 \mathrm{~s}$ after the weight sensor "feels" that there is no one inside. Thus, reducing standby power, which can be relatively inexpensive in many cases, can dramatically cut total energy use. 


\section{Case Studies}

The following case studies illustrate the implementations of state-of-the-art elevator technologies in major skyscraper projects in various parts of the world including: One World Trade Center in New York; Shanghai Tower in Shanghai; Burj Khalifa in Dubai; Kingdom Tower in Jeddah, Saudi Arabia; and the Empire State Building in New York. These projects are of national and international significance so that their sponsors, developers, and owners worked hard to implement the most advanced technologies in these buildings, including elevator technologies. Each case study starts by providing an overview of the building. Then, it explains technologies related to elevators structured according different topics.

\subsection{One World Trade Center, New York, USA}

Height: 541 m, 1776 feet

Floors above ground: 104; below ground: 5

Architect: Skidmore, Owings \& Merrill

Completion: 2014

\subsubsection{Building Overview}

The tower is the centerpiece of the 16-acre site where the twin towers stood before the 9/11 tragic event. Shaped like an obelisk with chamfered corners, One World Trade Center is the tallest building in the Americas. Designed by Skidmore, Owings, and Merrill (SOM), the tower not only establishes new architectural and safety standards, but it also employs state-of-the-art environmental and green features including sophisticated elevator systems. The advanced life-safety systems exceed that required by the New York City Building Code. The skyscraper's structure contains nearly 50,000 tons of steel and 180 thousand cubic yards of concrete, making the building strong enough to withstand explosions, storms, and earthquakes. Among the unique safety features are extra strong fireproofing and air-filtering systems for chemical and biological particles, as well as pressurized and extra-wide emergency stairs. These features, among many others; however, made the building the most expensive skyscraper in the world. According to the Emporis database, One World Trade Center's costs reached US \$3.9 billion. About 26,000 people have been involved in constructing the 104-story skyscraper [17,41].

\subsubsection{Elevator Systems}

One World Trade Center contains a total of 73 elevators and 11 escalators. Only ten elevators travel directly from the ground floor to the roof. The five service elevators can stop at every floor, while the elevators to the observation deck speed to the top without stopping. These express elevators are the fastest in the Western Hemisphere (they travel with a speed of $10.16 \mathrm{~m} / \mathrm{s}$ or 2000 feet-per-minute) and have a capacity of 4000 pounds. As such, the $394 \mathrm{~m}$ or1293-foot trip to the observation deck, located on the 102nd floor, takes about $40 \mathrm{~s}$. Tenants working higher than the 64th story take an express shuttle to the sky lobby on the 64th floor, where they transfer to "local" lifts that take them to upper floors (Figure 6). 

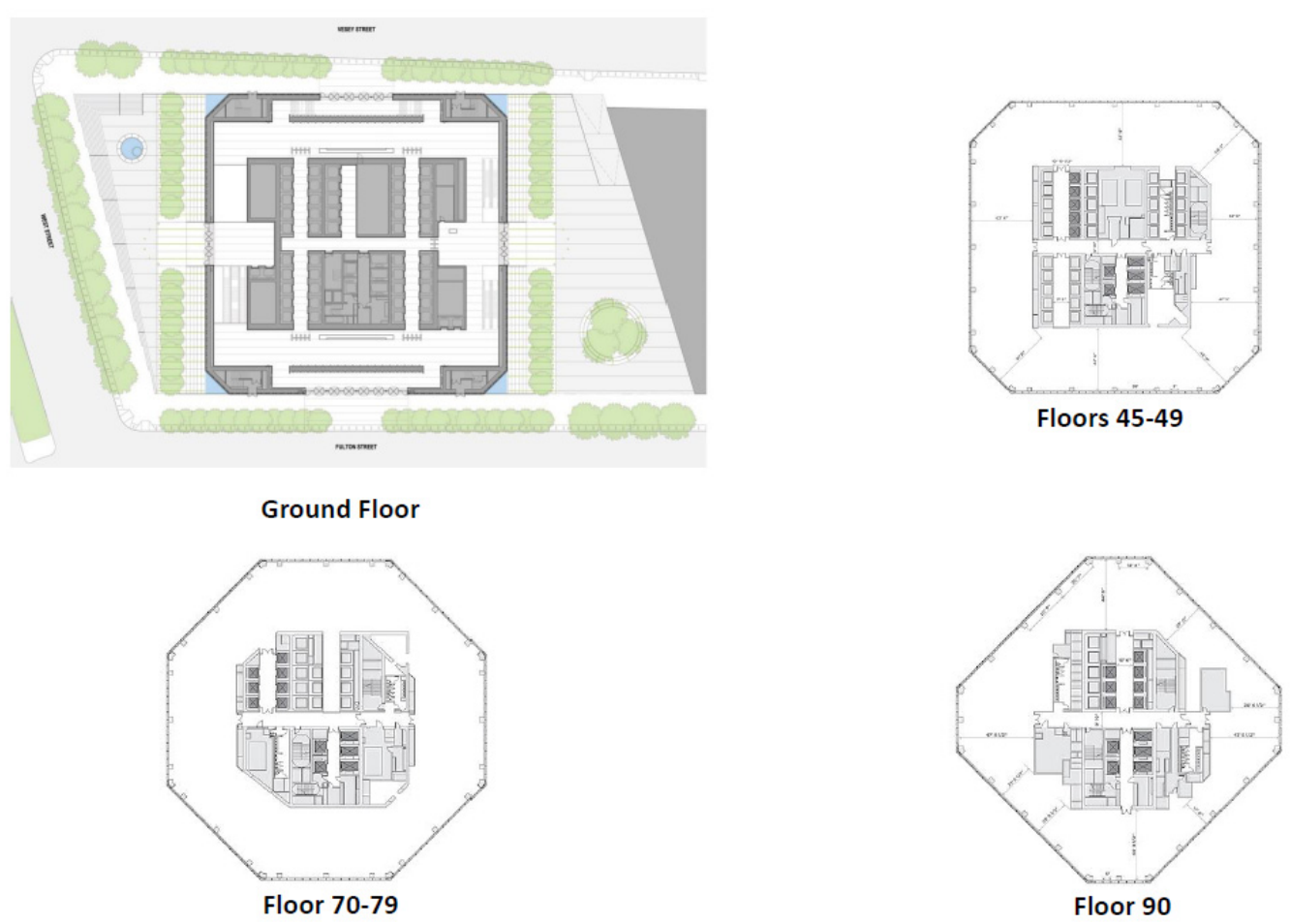

Figure 6. One World Trade Center. It contains a total of 73 elevators; ten travel directly from the ground floor to the top. The design employs state-of-the-art technologies in almost every aspect of elevators including: high-speed double-deck elevators that run at a speed of $10.16 \mathrm{~m} / \mathrm{s}$, computerized roller guides, air pressure differential system, destination dispatching system, and entertaining electronic displays. However, note that elevators continue to take up considerable space of the floor plans. (Source: http://www.SOM.com).

Originally, the intended speed for elevators was $9.1 \mathrm{~m}$ per second, but it was increased to $10.16 \mathrm{~m} / \mathrm{s}$ to accommodate the number of tourists who want to visit the One World Trade Center observation deck. The design team expected more than five million visitors a year to the observation deck $(14,000$ people a day) and 10,000 people working daily on the office floors [42]. One World Trade Center is expected to enjoy an annual "vertical ridership" of 3.5 million people in its elevators while traveling on 198 miles of steel cable [42]. Eight 2.3-ton electric motors installed on 1 WTC's roof power the high-speed elevators. Each elevator operates using a pulley-like system that consists of a cab and counterweights connected by a cable. There are 66 other elevators in the building, 20 of which run at $9.14 \mathrm{~m} / \mathrm{s}$. Together, One WTC's elevators use about 454,000 kg of counterweight to ascend and descend the building's hoistways.

\subsubsection{Computerized Roller Guides}

An elevator needs more than just robust motors and powerful current to enable it to travel long distances at high speeds. Like bullet trains, fast-moving elevators also require exceedingly smooth rails and rail joints to move swiftly. To provide a smoother ride, train-rail segments have been increased in length to reduce the number of joints over which a train must travel. For alignment precision considerations, the vertical positioning of elevator rails; however, limits their length to about $4.9 \mathrm{~m}$ (16 feet), which means any skyscraper will surely require a great number of rail joints. Elevators must 
also account for tiny changes in the distance between guide rails that occur because of changes in temperature (contraction and expansion), wind forces, and other conditions that cause skyscrapers to sway slightly throughout the course of a day and night. These factors prevent the achievement of a perfect plane for an elevator to travel in very tall buildings [42].

In response to this problem, ThyssenKrupp has devised for the One World Trade Center computerized roller guides that mitigate the impacts of the bumps in the guiderails by exerting forces in the opposite direction. Roller guides keep an elevator's wheels, known as rollers, in contact with the guide rails as the car ascends and descends. The rollers used at One WTC are made of polyurethane so they can absorb slight imperfections in the rail joints and are controlled by a system that pushes and pulls against the rails to prevent any misalignments or imperfections from causing shake and rattle. In other words, these active roller guide systems function as intelligent shock absorbers that respond in real-time. They simulate the function of a driver who knows that there is a large pothole on the road and swerves a bit to avoid it. For example, if the pothole was on the right-hand side of the road, the driver turns slightly to the left, and vice versa. Consequently, the express elevators not only move fast (25\% faster than the express elevators that served the former World Trade Center Twin Towers), but they are also motionless when compared to the former twin towers, and passengers experience no shake or rattle [42].

\subsubsection{Air Pressure Differential}

Air pressure differential is also a concern when designing and building high-speed elevator systems that travel long distances, such as the case in supertall and megatall skyscrapers. The first issue of air pressure is related to the elevators as they pass floors with great speed, resulting in air drag in the elevator shaft. Air-pressure effect is similar to that experienced in a subway: as a train pulls into the station, it pushes a wall of air in front of it. Similarly, when a typical 4500-kg car with a 7300-kg counterweight swiftly ascends or descends into the elevator shaft, it generates enormous air displacement. With an area of high pressure above the car and low pressure below it, the hoistway doors above the car get pushed into the hallway, and the hoistway doors below the car get sucked into the hoistway. In response to the problem, ThyssenKrupp attached wedge-shaped aluminum shrouds around the top and bottom of the cabs to make them more aerodynamic when they rush up and down the shafts. The resulting aerodynamic form of the cab reduces air resistance, minimizes air displacement, decreases door rattling, and reduces wind noise-the "whooshing” sound [42].

The second issue of air-pressure concerns passengers' comfort and safety, particularly related to the "ear-popping” effect as the elevator travels with higher speeds. This phenomenon results from a swift and drastic change in air pressure as the elevator ascends and descends rapidly, although this problem is more pronounced in the descending order. To appreciate the dynamic situation resulting from swift descent, it is important to note that elevators in super and mega tall buildings descend faster than a descending commercial airplane. That is, the landing process of an airplane may take about $30 \mathrm{~min}$, and this provides a plenty of time to adjust air pressure in the airplane. In contrast, elevators in very tall buildings might have just $30 \mathrm{~s}$ to adjust air pressure or to de-pressurize. This gives elevator's passengers limited time to adjust and forms the essence of the problem. In response, ThyssenKrupp's approach at One WTC was to pressurize cars (provide extra air pressure inside the cars) to compensate for pressure drops, then slowly releasing it to keep passengers' ears from popping. Through extensive research, 
ThyssenKrupp's engineers have found the optimal speed for fans that control air pressure inside cars while elevators descend swiftly. In all cases, however, because of the air-pressure problem, elevators continue to descend not faster than $10 \mathrm{~m}$ per second (33 feet/s) [42].

\subsubsection{Structural Safety}

It is worth mentioning that the former World Trade Center had one of the world's greatest elevator systems - 198 of the largest, fastest elevators. However, during the tragic 9/11 event, at least 200 people died inside the buildings' elevators, the biggest elevator tragedy in history. This problem was attributed to the steel exoskeleton structure of the towers, the vulnerability of which was revealed in this attack. In contrast, in One WTC the elevator hoistways run through the building's core, which is protected by a one-meter-thick concrete shell. In addition to protecting elevators in thick concrete walls, each floor contains a refuge area to protect tenants in case of an emergency situation, such as fire. Additional measures were taken to improve passengers' safety. Conventionally, if there is a fire, the emergency elevator stops just below the floor affected and the firefighters take the stairs to get to the source of the blaze. In One WTC, the shaft of the emergency elevator is kept at negative pressure to prevent smoke from entering. The cab has a second door, which, in emergencies can be opened onto a separate corridor, from which the firefighters can access the elevator [42].

\subsubsection{Destination Dispatching System}

For a faster service, a Destination Dispatching System was implemented, in which all the elevators are connected via an Intranet, and passengers headed for the same destination are grouped together and share an elevator. The employed destination dispatch system is used in 63 of the building's elevators. In order to improve security, obligatory building passes that contain information about the holders and where they work are implemented. When visitors swipe a badge at a turnstile, badge's data are passed on to the elevator. The digital display lights up with the number of the waiting elevator, almost in real-time. Visitors and employees who are authorized to access several floors can override the system and change their destination on a touch screen outside the elevator.

\subsubsection{Elevator Maintenance}

The elevator maintenance system at One WTC uses Microsoft's Azure Intelligent Systems Service. This system responds to problems proactively by continuously sending service engineers real-time data so that they can take steps to prevent elevators from breaking down. These data are entered into dynamic predictive models that help engineers to take precautionary actions. In case an elevator reports a problem, the system immediately suggests the most likely causes. This helps technicians more quickly diagnose and commence repairs, thereby reducing potential down time of the elevators [43].

\subsubsection{Entertainment}

Elevators traveling to the observatory tower contain large high-definition monitors. The 47-s (386-m; 1268-ft) ride features a breathtaking, immersive, three-dimensional animation that "recreates" the urban development of the New York City for the past 515 years, from the 1500s to today. This 
emotional and remarkable journey begins as the elevator "rises out of the rock and swampy waters that lay off Manhattan before humans decided to extend the island. In the 1600s, homes of colonists start materializing on the island's meadows. In the 1700s, the shoreline creeps farther south as the city transforms into colonial New York. By 1839, passengers can see the tidal strait known as the East river. For a few seconds in the late 20th century, the south tower of the original World Trade Center looms alongside the ascending elevator. Finally, steel beams and structural supports of the new tower spindle outward into existence, and the building appears to coalesce around the elevator just in time for arrival on the 102nd floor” [44]. One World Trade Center's observation deck, which comprises three levels, opened to the public just recently, on 29 May 2015 [45].

\subsection{Shanghai Tower, Shanghai, China}

Height: 632 m, 2073 feet

Floor above ground: 121; below ground: 5

Architect: Gensler

Completion: 2015

\subsubsection{Building Overview}

Shanghai Tower, a new iconic landmark in the ever evolving Shanghai skyline, displays an evocative, curved facade and spiraling form that symbolizes the dynamic emergence of modern China. It is the world's second tallest tower (next to Burj Khalifa); the tallest building in China; and the world's tallest double-skin building. It contains over four million square feet of above grade space and one and one-half million square feet below grade. The tower houses offices, hotel accommodations, commercial facilities, convention halls, exhibition halls, restaurants and culture and tourism facilities [17].

\subsubsection{Elevator Systems}

Produced by Mitsubishi, 106 elevators serve the tower's tenants and visitors by taking them to the various functions of the tower. Three sets of elevators, called bullet elevators, travel directly between the second basement level and the observation deck on the 119th floor. These elevators are the world's fastest, traveling at a speed of $18 \mathrm{~m}$ per second or $59 \mathrm{feet} / \mathrm{s}(1080 \mathrm{~m} / \mathrm{min}$ or $3543 \mathrm{feet} / \mathrm{min}$ —roughly $40.2 \mathrm{miles} / \mathrm{h}$ ). The past world record for elevator speed was that of Taipei 101 which travels at a speed of $16.8 \mathrm{~m}$ (55 feet) per second, approximately $1011 \mathrm{~m} / \mathrm{min}$. Consequently, the journey from the basement to the observation deck, a 565.4-m or 1855-feet journey, takes only about $32 \mathrm{~s}$ (Figures 7 and 8).

In addition, four sets of double-deck elevators travel at a world record of $10 \mathrm{~m}$ (33 feet) per second between the ground floor and the hotel lobby on the 101st floor. Noticeably, all elevators are equipped with energy-saving solutions, including regenerative converters and group-control systems, lowering energy use by up to 30 percent. Similar to the case of One WTC, aluminum covers at the top and bottom of the elevator cars are employed to reduce air resistance and wind noise at high speeds. Rounding out the tower's impressive elevator system is an emergency elevator which became the world's longest-traveling elevator, operating between the 121st floor and the 3rd basement level; a distance of almost 578.5 m (1900 feet) [17]. Like Otis’s original elevator, the new Mitsubishi moves by way of a 
pulley. However, the car hangs from one end of a set of advanced sfleX-rope cables, and a 13-ton counterweight hangs on the other. The sfleX-rope is made of high-intensity steel wire strands that are wrapped in plastic. It allows 85 percent more load to be handled under braking while only increasing the weight of the rope by 18 percent. A 310-kilowatt sophisticated motor at the top of the elevator shaft raises and lowers the car by turning the pulley [46].

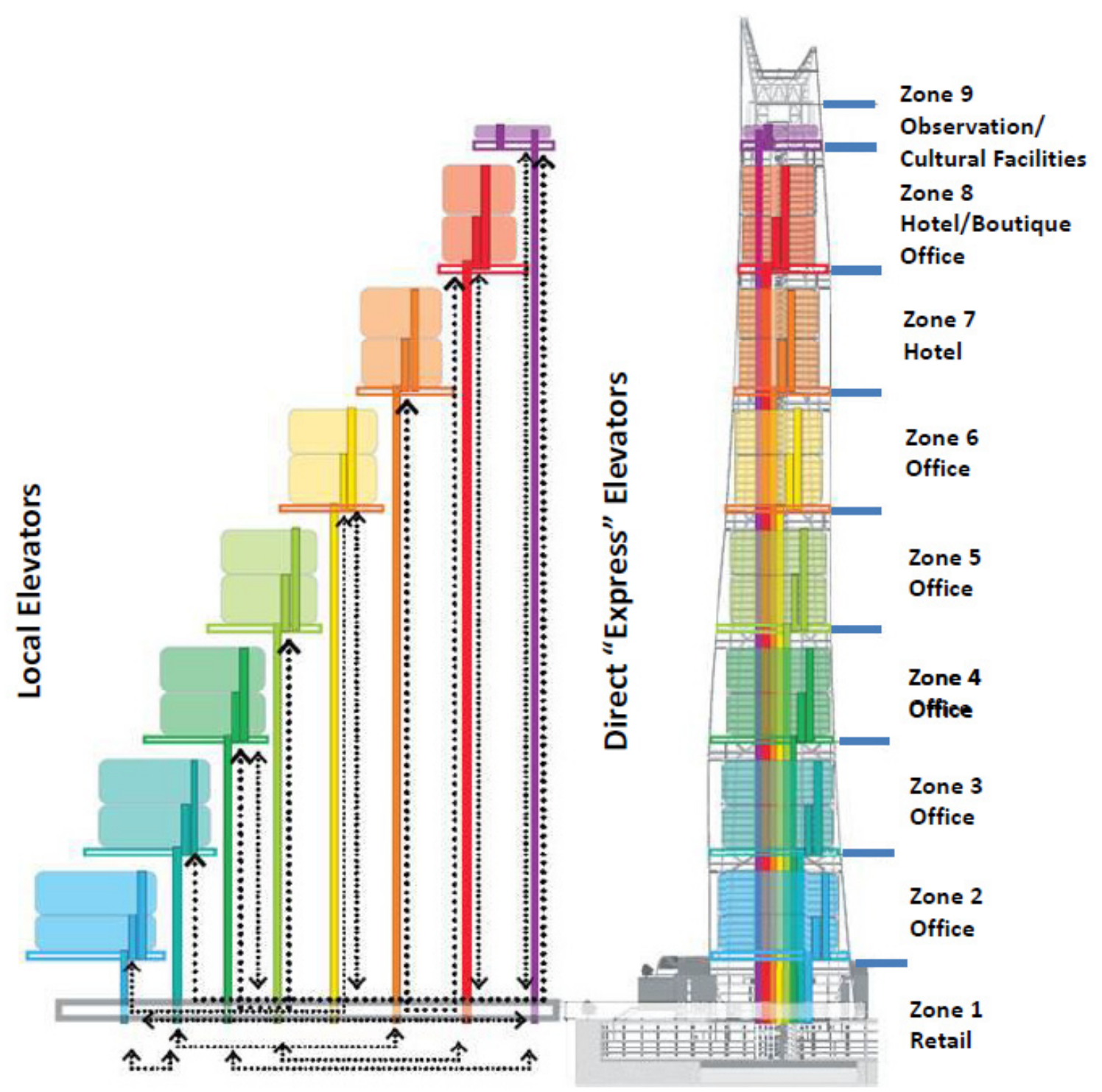

Figure 7. Shanghai Tower. Express and local elevators serve the 9 zones of the tower efficiently. (Source: http://www.Gensler.com). 


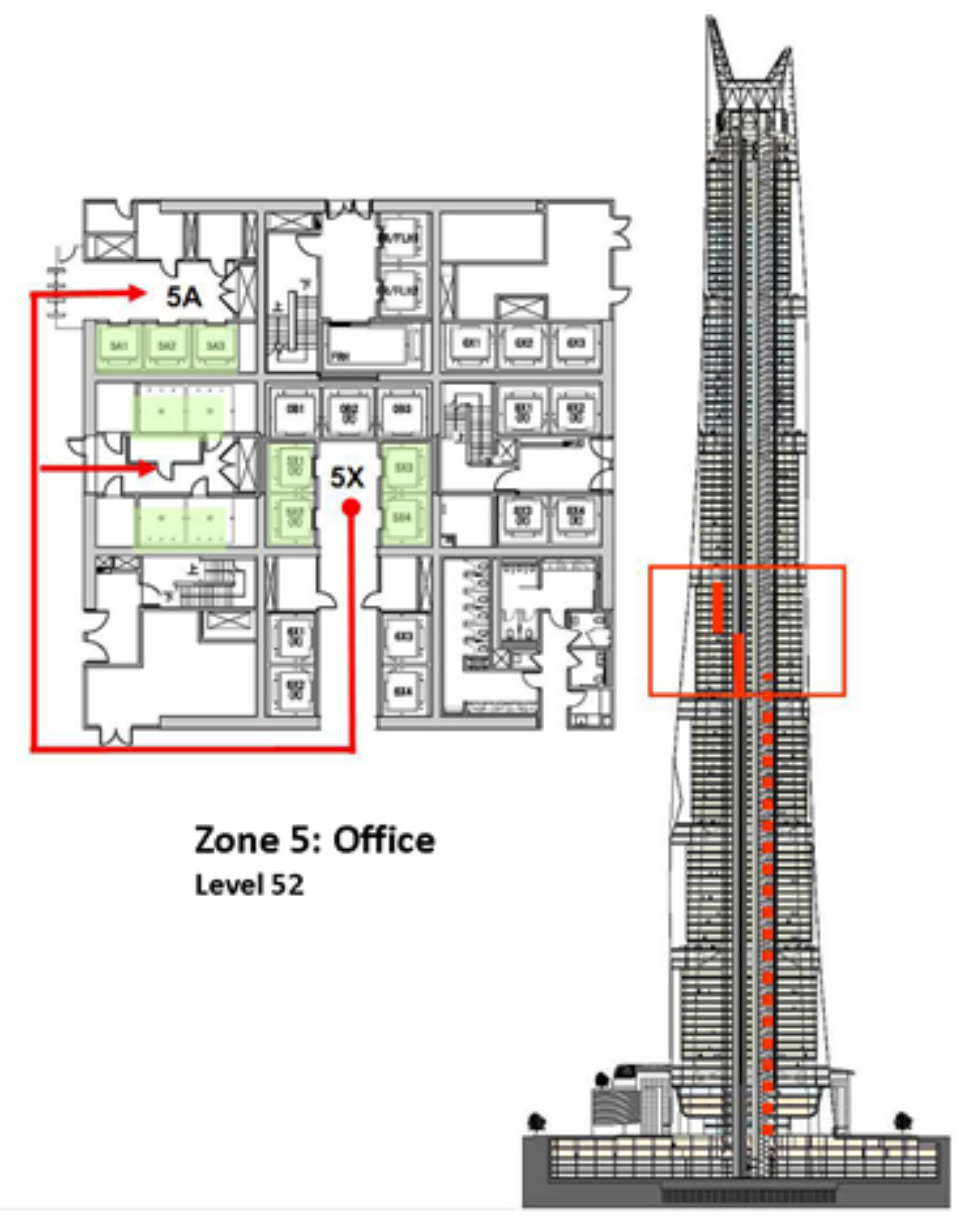

Figure 8. Shanghai Tower. Detail of elevator arrangement in Zone 5, Level 52. Passengers transfer from $5 \mathrm{X}$ express elevators to 5 A local elevators. (Source: http://www.Gensler.com).

\subsubsection{New Braking System}

In order to ensure safety during greater speed and longer travel distances, Mitsubishi had to come up with a new braking solution. In the event that "cables become transected," safety gears will automatically activate brakes, which will grab the guide rails. A new two-tier braking system that uses brake shoes made of ceramic is capable of handling shocks and excessive heat of 1000 degrees Celsius (1800 degrees Fahrenheit). Therefore, during normal operation, a disc brake stops the main pulley mechanism. If the system detects that a car that is moving too quickly, it triggers a mechanism at the base of the car to grip the rails, halting it within $15 \mathrm{~m}$ (50 feet).

\subsubsection{Other Technologies}

Similar to the case of One WTC, passengers feel much fewer vibrations during elevator travel due to installed active roller guides. Elevators travel on two sturdy steel rails, and the active roller guides absorb jiggle at high speeds by automatically counteracting shakes. Accelerometers attached to the car sense when it sways slightly, and then electromagnetic actuators inside the rollers nudge the car minutely in the opposite direction. In addition, sound insulation cages were installed around the cars to ensure a quiet ride. Further, a pneumatic system was implemented to handle air-pressure differential and to prevent ear 
popping. Finally, a central computer determines when and in what order to dispatch elevators to pick up passengers. This results in minimizing waiting time while preventing any two elevators from running side by side, which would otherwise create wind noise and excess pressure in the shaft $[17,46]$.

\subsection{Burj Khalifa, Dubai, UAE}

Height: 828 m; 2717 feet

Floors above ground: 163; below ground: 2

Architect: Skidmore, Owings \& Merrill

Completion: 2010

\subsubsection{Building Overview}

Burj Khalifa is the tallest building in the world. The tower was designed as a centerpiece of a grand plan for a large mixed-use development that will contain up to 30,000 homes, nine hotels, 19 residential towers, the Dubai Mall, 3 ha (7.5 acres) of parkland, and a 12 ha (30-acre) artificial lake, among other functions and uses. The tower can hold up to 35,000 people, and it contains swimming pools, 900 private apartments, 144 residences in the Armani section, 49 floors of corporate office suites, restaurants, sky lobbies, an observation deck, and the world's most advanced computerized "dancing fountain" on the lake [17].

\subsubsection{Elevator Systems}

Burj Khalifa contains 57 elevators, of which, two are double-deck elevators used exclusively for travel to the observation deck. The tower boasts a number of outstanding elevator features including: long travel distance of $504 \mathrm{~m}$ (1654 feet), the highest elevator landing at $638 \mathrm{~m}$ (2093 feet), and fast double-deck elevators that travel with a speed of $10 \mathrm{~m}$ per second or 1969 feet per minute. Double-deck elevators, with built-in light and entertainment features including LCD displays, carry visitors to "At The Top, Burj Khalifa”, the world's highest outdoor observation deck located on the 124th level. They also serve office users transferring at the sky lobby at level 123. These elevators have a capacity of 12 to 14 people per cabin [47].

In Burj Khalifa, elevators are arranged in zones to serve different functions according to a sky lobby system. The sky lobby is an intermediate floor where residents, guests and executives change from an express elevator to a local elevator, which stops at every floor within a certain segment of the building. Burj Khalifa's sky lobbies are located on levels 43, 76 and 123 and include lounge areas and kiosks, among other amenities. Another highlight is the state-of-the-art circular observation elevator that serves three floors in the Armani Hotel restaurant area. All elevators have been supplied and installed by Otis, Farmington, CT, USA.

Unique to the elevators are 25 machine-room-less (MRL) elevators featuring flat, polyurethane coated belts instead of steel ropes, and gearless drives instead of bulky motors, which eliminated the need for engine rooms. These features reduce energy consumption by up to $50 \%$ when compared to conventional units. Called energy-efficient Gen 2, the system does not require lubrication, eliminating the need for storage, cleanup and disposal of hazardous waste. A computerized destination dispatching 
system also was implemented. Since the cables are very long, under strong winds, their movements may become dangerous and damage the elevators shafts. "Sway sensors" are incorporated toward the top of the elevator shafts to inform if the movements and vibrations of elevator ropes become too strong. In that case, elevators get shutdown temporarily.

\subsubsection{Safety Systems}

Accommodating up to 35,000 people presents potential safety concerns and hazards, and "the highest-risk part of the Burj Khalifa is its high speed elevators" [48]. In response, the designers of Burj Khalifa have equipped the elevators with safety devices and included features such as fireproof concrete and sills so that water from sprinklers does not flood the shafts. Burj Khalifa uses an intricate system of elevators to aid with fire safety. In case of emergency, fast and large service elevators (with $5500 \mathrm{~kg}$ capacity) can be utilized to transport the building's occupants.

Ten elevators enjoy "lifeboat" features, meaning that passengers are encapsulated in a completely fire-resistant environment. These elevators are operable on emergency back-up power, and can be manually controlled using a camera and a joystick by the Dubai Civil Defense. The "lifeboat evacuation" operation mode enables emergency responders to take occupants to refuge areas, which are two-hour fire-resistant areas that are pressurized (to minimize the migration of smoke into the compartment), air-conditioned, and are placed approximately every 25 floors. They also contain LCD monitors to convey evacuation instructions and critical information. The refuge areas are connected to multiple staircases, which are protected by highly fire- resistant concrete walls. Occupants walking down the stairways during an evacuation can rest safely in the refuge areas. Multi-alarm sensors of smoke, heat and motion are located in all rooms throughout the building. In emergency situations such as a fire, the system will immediately notify occupants through an emergency voice/alarm communication system in multiple languages. The building's ventilation system also helps with the issue of smoke and other toxins $[49,50]$.

\subsection{Kingdom Tower, Jeddah, Saudi Arabia}

Height: 1000 m, 3280 feet

Number of floors: 170

Architect: Adrian Smith \& Gordon Gill Architecture

Completion: 2019, anticipated

\subsubsection{Building Overview}

The Kingdom Tower is being built over an area of 85,000 $\mathrm{m}^{2}$ forming the centerpiece of the first phase of the Kingdom City, which encompasses 1.5 million square meters. The Kingdom City will comprise 5.3 million square meters of multi-purpose buildings (including the tower), a mall, a large mosque for 12,000 worshippers, and other residential and commercial buildings. The Kingdom Tower will feature 170 stories that include: seven floors for the five-star, 200-room Four Seasons hotel; 11 stories for 121 luxury service apartments; seven stories for offices; 61 stories for 318 housing units of various types along with amenities; two sky lobbies; world's highest observation deck located at a 
height of $644 \mathrm{~m}$; eight, double-height full refuge floors that are fire resistant; and a sky terrace-roughly $30 \mathrm{~m}$ (98 feet) in diameter-at level 157 [51].

\subsubsection{Elevator Systems}

According to KONE, the tower will be equipped with a total of 65 elevators including: 21 MonoSpace elevators; 29 MiniSpace elevators; seven DoubleDeck MiniSpace elevators; and service elevators. The double-deck elevators will be the world's longest and highest with a travel speed similar to that of Burj Khalifa and Shanghai Tower of $10 \mathrm{~m} / \mathrm{s}$. They will be traveling $660 \mathrm{~m}$ (2165 feet) directly to the observation deck [51]. The building will also contain eight TravelMaster 110 escalators.

In order to travel to the observation deck, a single elevator in the Kingdom Tower would require nearly 20 tons (18 metric tons) of steel rope; which would pose serious construction problems. Fortunately, the UltraRope hoisting technology makes this possible. As explained earlier, the carbon-fiber UltraRope, is lighter and stronger than steel rope, which consequently reduces weight and motor size, decreases power consumption by approximately $21 \%$, and allows a greater lift height. The UltraRope has great tensile strength, meaning it is hard to break when its ends are pulled. That strength comes from the chemical bonds between carbon atoms, the same process that gives such strength to diamonds. In addition, the UltraRope system requires less maintenance and lasts double the time of steel ropes. Carbon fiber sways less as skyscrapers move in high winds. Usually, a high wind can cause a building's lifts to be shut down, but the utilization of carbon-fiber ropes will make this happen less often.

Further, the latest KONE “People Flow Intelligence” systems will be implemented to smooth the flow of people to and from elevators and to reduce waiting time. Interestingly, high-rolling residents and VIP visitors will also be able to communicate directly with the lifts through their smart phones. They will be able to remotely call the elevator as they step out of their cars, for example, so that they will find the elevator waiting when they arrive in the lobby.

\subsection{Empire State Building, New York, USA}

Height: 381 m; 1250 feet

Floors above ground: 102; below ground: 1

Architect: Shreve, Lamb and Harmon

Completion: 1931

\subsubsection{Building Overview}

The Empire State Building (ESB) is a 102-story skyscraper located in Midtown Manhattan, New York City. The building's construction was completed in 1931 and was the tallest building in the United States for almost four decades, until the topping out of the World Trade Center's North Tower in the late 1970s. With its beautiful Art Deco Style, elegant profile, and distinctive height and history, the building enjoys an important place in American culture. It was named as one of the Seven Wonders of the Modern World by the American Society of Civil Engineers. Its 260,128 $\mathrm{m}^{2}\left(2,800,000 \mathrm{ft}^{2}\right)$ of leasable office space attracts a wide range of businesses drawn by the building's prestige, its unmatched skyline views and convenient location at the center of Manhattan's mass-transit system. Its observatory on the 86th floor 
attracts about 4 million visitors yearly. The ESB has long represented a symbol of power of New York City, and also has become a symbol of "green power efficiencies," and was recently nicknamed "the Green Empire” [15,18].

\subsubsection{Green Retrofit Project}

The ESB green retrofit project began in 2009 as part of the Clinton Global Initiative. In 2010, the 80-year old building underwent a one- half billion dollar retrofit, with the overall goal to transform the building into a more energy efficient and eco-friendly structure. The environmental upgrade of the building is the largest retrofit of its kind to date in the United States. "It is expected to reduce energy use by more than US \$4.4 million annually, cut carbon emissions by 105,000 metric tons over a 15-year period and provide a payback in slightly more than three years" [52]. Reducing the building's carbon footprint by 105,000 metric tons is equivalent to removing 20,000 cars off the road.

\subsubsection{Elevator Green Retrofit}

Upgrading the elevator system was particularly remarkable because the new system saves energy in multiple ways. The employed regenerative system, as explained earlier, harvests the "waste energy" from braking, of which elevators do frequently. Conventional elevator machinery can lose more than $30 \%$ of its energy in the form of waste heat, and the new retrofit reduces the loss to only five percent. The new elevator system channels the rest of energy back into the building's electrical system. The second means of savings is a direct result of the first. In a conventional elevator system, waste heat gathers in the machine room, which then requires substantial air conditioning to prevent overheating. In contrast, the regenerative system does not have this problem because heat has already been captured, harnessed, and channeled to the electrical system as "surplus" power. "The trick behind the system is a gearless technology based around a permanent magnet AC motor. A gearless machine operating at less than $240 \mathrm{rpm}$ can reach the same speed as a geared machine at $1800 \mathrm{rpm}$ ” [13]. Additional savings are achieved by having the new system's motor consumes zero energy when the elevator is not in use. Finally, the new elevator system is designed to accommodate high efficiency LED lighting in the cabs. Collectively, the new elevator system results in significant savings that reduce demand on the city power grid $[13,14,53]$.

\section{Other Technologies}

By reviewing new elevator technologies, we find that the main focus has been on reducing energy consumption. However, other technological advances also offer a range of benefits. For example, Marcello Personeni [54] explains that the closed-loop door technology system provides sensors that monitor and adjust the speed of the car door operators to account for changes in temperature, humidity, and wind, among other factors. As a result, this technology can make door openings and closings smoother and more controlled. In terms of aesthetics and imageability, owners and architects see the elevator as an extension of the lobby, a powerful symbol of building quality. Improved mechanical, illumination, and control features can improve perceived quality. Flat-panel screens in elevator cabs can be used for many purposes — from delivering the day's headlines to advertising purposes. They can be 
used to welcome new tenants to a building or explain the renovation on a particular floor. In the event of emergency, display screens in lobbies can convey important information and messages to tenants, visitors, first responders and emergency personnel. The screens can also communicate helpful, up-to-date information about the surrounding neighborhood, such as street closures and alternate routes.

Green technology extends beyond the elevator's operations. For example, cab walls could be composed of 100-percent recycled and recovered wood. Green elevators can improve building health by avoiding toxic volatile organic compounds (VOC) that pollute indoor air. Low-VOC finishing materials in a green elevator design can include components made of bamboo, recycled carpet, and hard surface coverings with low VOC sealants and adhesives. Interestingly, some elevator companies, such as Otis, have "doubled" their commitment to the environment by not only engineering energy-saving products but also by manufacturing them in a way that is kinder to the environment [23].

In addition, important technological advances have improved elevator speeds. In today's fast-paced environment, speedy elevators are needed to move passengers to their destinations in the shortest time possible. They help reduce overcrowding in the buildings' lobbies, sky lobbies, and corridors. Studies also show that people are more sensitive about waiting times for elevators than any other means of transport, such as buses, trains or boats. A recent survey revealed a maximum elevator wait time of $28 \mathrm{~s}$; after that, people started to become restless and show dissatisfaction signs with the elevator system. Further, the taller a buildings gets, the faster we need elevators to go so as to keep the travel time at an acceptable level. In relatively short buildings the time spent in an elevator could be insignificant, but in the case of tall, supertall or megatall buildings, speed becomes essential [17].

Indeed, advancements in elevator speeds have been remarkable. The first commercial passenger elevator, installed by Otis Elevator Company in 1857, climbed $0.2 \mathrm{~m} / \mathrm{s}$ ( $0.67 \mathrm{feet} / \mathrm{s} ; 40 \mathrm{feet} / \mathrm{min})$. In the Woolworth Building, the tallest in the world at the time of its completion in 1913, two cars ran at $3.5 \mathrm{~m}$ per second. Later, elevators at the Empire State Building traveled at $6 \mathrm{~m}$ per second. At the original trade center, express cars rattled upward at $8 \mathrm{~m} / \mathrm{s}$. In comparison, Shanghai Tower's elevators now travel with a speed of $18 \mathrm{~m} / \mathrm{s}$. Further, Hitachi is installing new elevators in CTF Finance Center in China, with a speed of $20 \mathrm{~m} / \mathrm{s}$ (66 feet/s), to be completed in 2016. As such, in a period of about 150 years, elevator speed has increased from $0.2 \mathrm{~m} / \mathrm{s}$ to $20 \mathrm{~m} / \mathrm{s}$. This means that the elevator speed has increased 100 times_an impressive technological advancement (Table 1).

To enable higher travel in a single trip, elevator companies are continuing to research and develop means to improve braking systems. The challenge of creating a braking system for an elevator that can reach greater heights is linked to the speed a potential falling car could reach. If one of the cars were to plummet, it could reach a speed of up to 45 miles/h. Trying to stop a car with a considerable weight at that speed would generate a serious amount of heat, as much as 300 degrees Celsius (572 degrees Fahrenheit). Otis is working on systems that are able to stop 16 metric tons (35,274 pounds) of an elevator and cable falling from the top of a kilometer-tall tower [17].

Since elevator systems are becoming more complex and reliant on computerized databases, it is important to protect these systems from hackers. For example, in the TWIN system, two cabs on top of each other run in the same shaft. The computerized system, empowered by distance-sensors, ensures a safe distance between the upper and lower cabs. If the TWIN systems were hacked, then these cabs would likely crash into each other, which could lead to a substantial disaster. Similarly, advanced destination dispatching systems are helping smooth traffic flow and are incorporating security 
components so that the system knows who and when individuals enter and exit the building. Hacking these systems could result in a chaotic passenger traffic flow and confuse surveillance activities. These incidences, if they were to occur, have the potential to damage the reputation of the high-rise industry and the "green" thesis of building tall versus sprawl. As such, protecting elevator systems must be a top priority.

Table 1. Buildings with the fastest elevators (Source: Emporis).

\begin{tabular}{|c|c|c|c|c|c|}
\hline & Building & $\begin{array}{c}\text { Speed in Seconds } \\
\text { Meter (feet) }\end{array}$ & $\begin{array}{c}\text { Year of } \\
\text { Completion }\end{array}$ & $\begin{array}{l}\text { Building's Height } \\
\text { Meter (feet) }\end{array}$ & $\begin{array}{l}\text { Elevator } \\
\text { Supplier }\end{array}$ \\
\hline \multicolumn{6}{|c|}{ Future Buildings } \\
\hline 1 & CTF Finance Center, Guangzhou, China & $20(66)$ & 2016 & 530 (1739) & Hitachi \\
\hline 2 & Kingdom Tower, Jeddah, Saudi Arabia & $10(33)$ & 2018 & $1000(3280)$ & KONE \\
\hline \multicolumn{6}{|c|}{ Existing Buildings } \\
\hline & Building & $\begin{array}{l}\text { Speed in Seconds } \\
\text { Meter (feet) }\end{array}$ & $\begin{array}{c}\text { Year of } \\
\text { Completion }\end{array}$ & $\begin{array}{l}\text { Building's Height } \\
\text { (m/feet) }\end{array}$ & $\begin{array}{l}\text { Elevator } \\
\text { Supplier }\end{array}$ \\
\hline 1 & Shanghai Tower, Shanghai, China & $18(59)$ & 2015 & $632(2074)$ & Mitsubishi \\
\hline 2 & Taipei 101-Taipei, Taiwan & $16.8(55)$ & 2004 & $509(1670)$ & Toshiba \\
\hline 3 & $\begin{array}{c}\text { Yokohama Landmark Tower-Yokohama, } \\
\text { Japan }\end{array}$ & $12.5(41)$ & 1993 & $296(971)$ & Mitsubishi \\
\hline 4 & $\begin{array}{c}\text { One World Trade Center, New York City, } \\
\text { U.S.A. }\end{array}$ & $10.16(33.33)$ & 2014 & $541(1776)$ & $\begin{array}{l}\text { ThyssenK } \\
\text { rupp }\end{array}$ \\
\hline 5 & Burj Khalifa—Dubai, U.A.E. & $10(33)$ & 2010 & $828(2717)$ & Otis \\
\hline 6 & Sunshine 60 Building_-Tokyo, Japan & $10(33)$ & 1978 & $240(787)$ & Mitsubishi \\
\hline 7 & $\begin{array}{c}\text { Shanghai World Financial Center-Shanghai, } \\
\text { China }\end{array}$ & $10(33)$ & 2008 & $492(1614)$ & $\begin{array}{l}\text { ThyssenK } \\
\text { rupp }\end{array}$ \\
\hline 8 & $\begin{array}{c}\text { China World Trade Center Tower III—Beijing, } \\
\text { China }\end{array}$ & $10(33)$ & 2010 & 330 (1083) & Schindler \\
\hline 9 & John Hancock Center, Chicago, U.S.A & $9.1(30)$ & 1969 & 344 (1129) & Otis \\
\hline 10 & Jin Mao, Shanghai, China & $9(29.5)$ & 1999 & $421(1381)$ & Mitsubishi \\
\hline
\end{tabular}

\section{Future Developments}

Future research will continue to focus on the development of space-saving and energy-efficient elevators that employ efficient motors, stronger materials, and smarter dispatching systems. Some research is looking into providing zero-energy or even "positive"-energy elevators. The elevator industry has been working on energy efficiency long before the term "green" became mainstream, and its extensive experience ambitious agenda will hopefully culminate in the "positive-energy" elevator. For example, some companies are working on solar elevators where solar panels installed on the top of the hoistway will generate power to run the elevator and supply surplus power to the city power grid. Among the exciting futuristic elevator designs is the electromagnetic levitation system [55].

\subsection{Electromagnetic Levitation Technology}

Electromagnetic Levitation Technology, or maglev for short, makes super high-speed trains run frictionless along a track by applying magnetic power. ThyssenKrupp is working on a "multi” system, 
a rope-free elevator system that applies the same concept but on the vertical plane. The "multi" will move multiple cabins vertically and horizontally in a loop. It aims to increase the tube transport capacity by up to $50 \%$ with a continuous flow speed of $5 \mathrm{~m} / \mathrm{s}$ and cabin arrivals every 15-30 s, whilst offering significant space saving because the compartments will be much smaller in size. Current elevator and escalator footprints can occupy up to $40 \%$ of a building's floor (Figure 9).

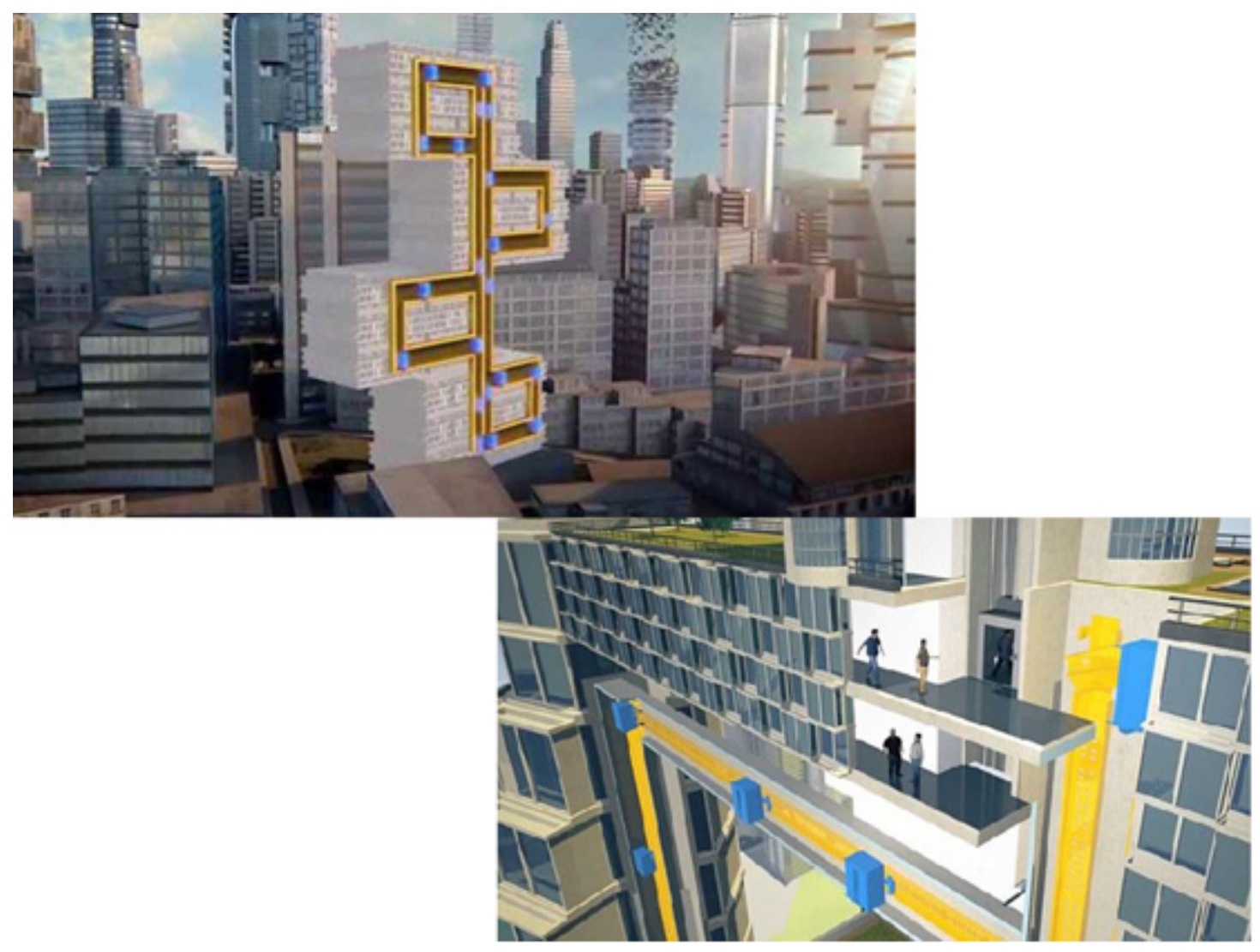

Figure 9. ThyssenKrupp is working on a "multi” system, a rope-free elevator system that applies Electromagnetic Levitation Technology on the vertical plane. The "multi” will move multiple cabins vertically and horizontally in a loop. It aims to increase the tube transport capacity by up to $50 \%$ with a continuous flow speed of $5 \mathrm{~m} / \mathrm{s}$ and cabin arrivals every 15-30 s, whilst offering significant space saving because the compartments will be much smaller in size. (Source: http://www.ThyssenKrupp.com).

According to Daniel Levinson Wilk, skyscraper heights have been always limited by the fact that, proportionally speaking, the shafts take up more and more space the higher buildings go. ThyssenKrupp expects that the space devoted to elevators can be cut by as much as half with the "multi." Further, this can significantly affect the economics of skyscrapers. Less space for elevators means more leasable space, which, in turn, makes the prospect of constructing a tall building with "multi" more appealing to developers and investors. Antony Wood and Corey Baitz commented that as the maglev system enables non-linear, non-vertical paths, it will fundamentally change the way we design tall buildings by improving building's interior connectivity and empowering architects to invent exciting architectural forms for high-rise development [56]. The first "multi" unit will be tested in the coming years in the 
company’s test tower in Rottweiler, Germany [17]. Other elevator companies are working on similar maglev systems.

\subsection{Circulating Multi-Car Elevator System}

The Circulating Multi-Car Elevator System comprises multiple cars that travel along the shaft in a circular movement by using a rotary magnetic array propulsion wheel. This system resembles a Ferris Wheel, but each car has a motor so that it can operate independently while not requiring counterweights. The circulating multi-car elevator promises to increase capacity, reduce the required number of shafts, and reduce waiting time. Using a one-tenth-scale model, Hitachi has successfully verified this elevator system. This model will enjoy similar advantages of the "multi" solution presented by ThyssenKrupp. However, the present prototype will need further developments to meet international safety standards [17].

\subsection{Vertical Subway Concept}

For years, research has focused on decreasing the amount of space required for elevator shafts to increase leasable space. One proposal is for an elevator system that mimics the train system that uses rail but by flipping the system vertically. Simply, this entails replacing elevators' ropes with rails. Such a system is expected to save on space up to $30 \%$ for single-deck elevators and $60 \%$ for double-deck elevators. Called Vertrak, the system maximizes space efficiency by accommodating multiple cars in one shaft. Overall, the proposed system has the potential to revolutionize vertical transportation. However, it raises unresolved safety concerns related to applying brakes at high speeds [54].

\subsection{Space Lifts}

Science fiction's research and developments continue to provide visionary proposals far from being attainable in the near future. One research example has suggested a "Space Lift" that intends to create a direct connection with outer space by using elevators instead of space shuttles. A Tokyo-based Obayashi Corporation desires to build an elevator that would take passengers skyward to a station 36,000 km (22,000 miles) above Earth with a speed exceeding $60 \mathrm{~m} / \mathrm{s}$ (197 feet/s) or $124 \mathrm{miles} / \mathrm{h}$ [17,55]. Building one would mean lowering a cable from a satellite in a geosynchronous orbit above the Earth's equator while deploying a counterbalancing cable out into space. The cable from the Earth to the satellite would not be a classic lift rope because it would not, itself, move. However, it would perform a similar function of support as robotic cars crawl up and down it, ferrying people and equipment to and from the satellite-whence they could depart into the cosmos. Among the major obstacles to achieving such a vision is lacking strong and light materials needed to construct the extremely long elevator's rope. Although carbon nanotube technology has been promising to provide such materials, the technology seems to be lingering behind. While the Space Lift's research may not directly concern skyscrapers, it may benefit their development in the future.

\section{Concluding Remarks}

This paper highlighted recent advances in elevator technology and illustrates their implementations in recent major projects around the world. It maps out, organizes, and collates significant accomplishments 
on the multiple aspects of elevator design including increasing speed, saving energy, reducing wait time, decreasing costs, all of which serves to enable the construction of taller and taller buildings. New elevator technologies harness heat resistant brakes, mitigate excess vibration and adjust for air pressure to prevent ear blockages. New elevators feature several advanced technologies designed to improve ride quality, safety and logistics. A closer look at these advances reveals how far elevator technology has advanced since the first Otis passenger elevator lifted shoppers from the ground floor of a New York City department store in 1857 (Figure 10).
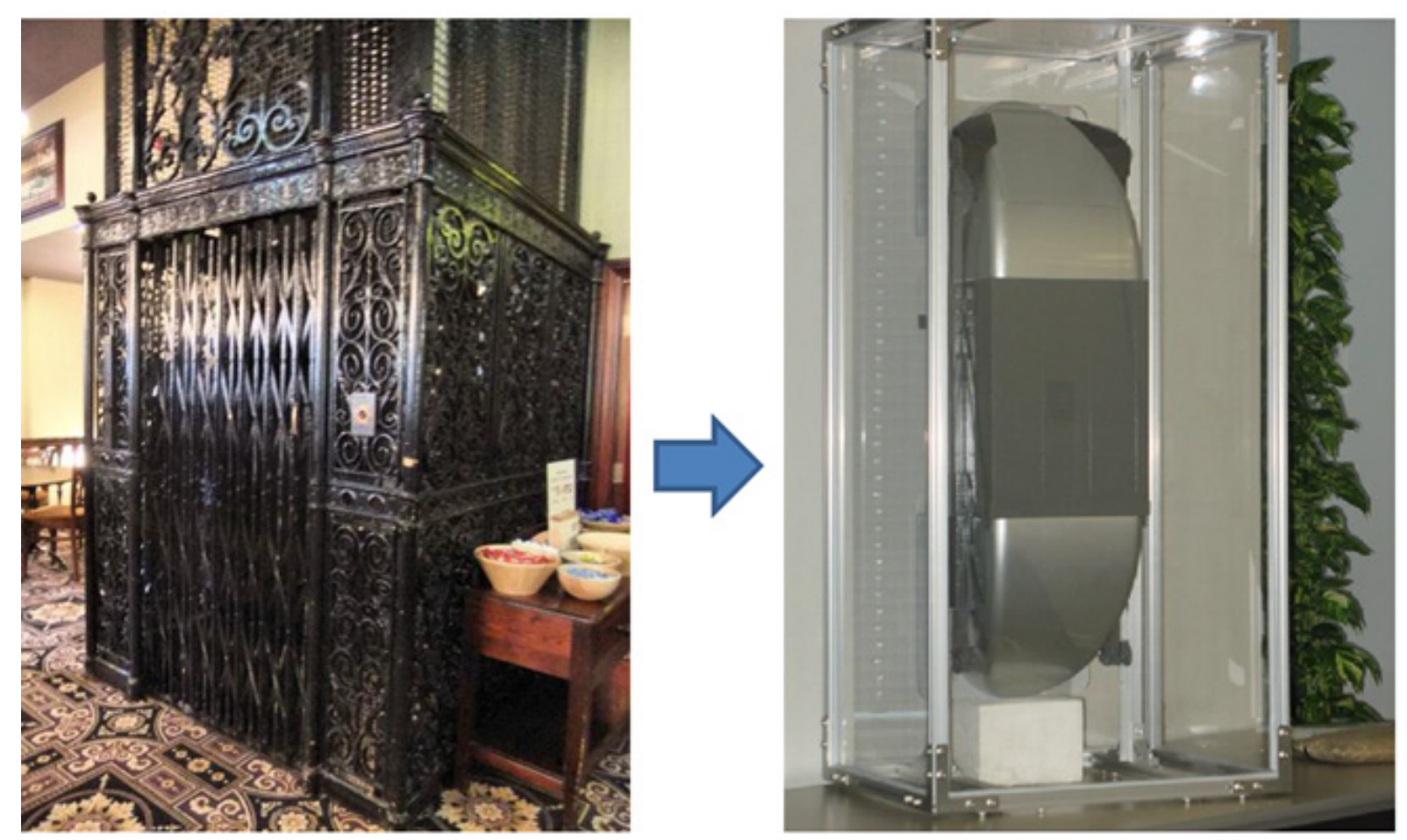

Figure 10. Left is a photograph of the Otis elevator introduced in 1856. It is currently housed in the Gardner's Warehouse in Glasgow, Scotland. Right is a photograph of Mitsubishi elevator installed in the recently completed Shanghai Tower in Shanghai, China. Otis elevator ran at a speed of about $0.2 \mathrm{~m} / \mathrm{s}$, while Mitsubishi runs at a speed of $18 \mathrm{~m} / \mathrm{s}$. Hitachi is installing new elevators in the CTF Finance Center in China, with a speed of $20 \mathrm{~m} / \mathrm{s}$, to be completed in 2016. As such, in a period of about one and a half century, the elevator's speed was increased about 100 times-testifying impressive technological advancement. (Source: Left, Wikimedia, attribution: Zeddy; Right, mitsubishielevator.com).

Indeed, over the past 150 years, elevators have witnessed outstanding technological leaps. Steam powered elevators were introduced in the 1850s. An important development in elevators was the introduction of a safety device, elevator brakes by Elisha Otis, which were demonstrated at the Crystal Palace Exposition in New York in 1854. This safety feature was a defining moment in elevator development and paved the way for the proliferation of skyscrapers. Thirteen years later, Elisha's sons went on to found Otis Brothers and Company in Yonkers, NY, USA, eventually to achieve mass production of elevators. In the 1870s, the hydraulic elevator replaced the steam power elevator. Later, the electric elevator evolved rapidly, allowing the travel of greater distance and hence allowing the construction of taller structures. By 1903, advancement in electric elevators made the construction of one hundred-plus story buildings 
to become possible. Other notable technological advancements included the introduction of push-button controls and signal systems, safety measures, and the replacement of manual rope-driven switching and braking with electromagnet technology [17].

The future of elevators is sky high. The simultaneous demand for more space and the lack of developable land in modern cities means that we will be building up more often, and cutting edge elevator technology will play a critical role in urban development. For example, in China, where an extraordinary economic boom has led to unprecedented urbanization, more than 700,000 lifts are being installed a year. This is as many elevators as exist in the entire German market [57]. Meanwhile, skyrocketing land values in many cities, for example London and New York, have led to the development of more towers. In London, where the population is expected to grow by one million people over the next decade, 135 new towers are current under construction, with more in the pipeline, according to a 2014 CBRE report. By 2030, nearly $70 \%$ of the world's population will be living in cities, and there won't be enough space, even in the outskirts. In order to accommodate all of the urban population, buildings will continue to grow taller [57]. For example, the New York City plans to build several ultra-tall buildings—projects include the Nordstrom Tower (547 m; 1795 feet), 432 Park Avenue (426 m; 1396 feet), 111 West 57th Street (435 m; 1428 feet), the centerpiece skyscraper of Hudson Yards in Midtown West (408 m; 1337 feet) and One Vanderbilt (461 m; 1514 feet) near Times Square. Massive urbanization forces will continue to push elevator companies to further innovate and to move genius concepts from paper to reality. The results will be improved speed, capacity, control, energy efficiency, comfort and safety; features that will enhance the sustainability of future high-rise developments [58].

Massive urbanization also places a huge demand on the environment, and there will continue to be pressure to incorporate "green" elevators. Of course, there is an upfront cost to energy efficient elevators, and the recoup period varies. Unfortunately, most of the "green" features for elevators are not entitled for governmental incentives, grants, or discounts. Many Energy Research and Development Authority programs in the United States that offer environmental upgrades continue to be in flux concerning elevator green features. Elevator manufacturers are becomingly gradually involved as a valuable resource to LEED registered projects. In-depth knowledge of the LEED process is needed to ensure that the elevators used in a project can obtain the deserved points for LEED certification.

Although "green" elevators are mostly not entitled for financial incentives, green elevators are relatively "affordable" when compared to the total costs of skyscrapers. For example, the total cost of elevators in the One World Trade Center was only two percent of the total cost of the tower (US \$88 million for elevators; US \$3.9 billion for tower). Similarly, the total cost of elevators in Burj Khalifa was about three percent of the total cost of the tower (US \$50 million for elevators; US \$1.5 billion for tower). As such, building owners and developers should not be discouraged from implementing "green” and state-of-the-art elevators [17].

Skyscrapers are built to last longer than regular buildings, and therefore, "green” investments could be worthwhile. As explained earlier, the 85-year old Empire State Building (ETB) underwent a major "green" retrofit that will extend its lifetime for several decades. As such, although the ESB was built with "lower-end" materials and technologies, its lifetime will now stretch to over one century. How about the new skyscrapers that are built with stronger materials today? Surely, many of these will last well over one century. As such, the long-term benefits of "green" investments in these buildings should be worthwhile [59,60]. 


\section{Future Research}

Elevator technology will continue to play a critical role in urban development, and cannot be viewed as a "stand-alone" function. Rather, an inter-disciplinary, comprehensive approach to design must be undertaken to ensure that vertical transportation systems can not only optimally function within a particular tower, but help the tower meet its broader urban design goals. Much of the available literature on elevator development and implementation de-emphasizes the role of urban designers, architects and interior designers in promoting effective solutions. John Mizon has pointed out that vertical transportation solutions have often been duplicated despite drastic changes in functionalities of tall buildings [61]. For example, we have seen in the past decade a noticeable shift from single-use to mixed-used high-rises. Further, Mizon explains that as buildings are becoming taller, we need to invent new approaches to vertical transportation. Unlike single-use developments, in mixed-use developments elevators have a completely different scope with respect to waiting times, with traffic peaking in a relatively smaller time frame.

"Vertical urban design" in tall buildings may examine how new innovative forms and shapes empowered by free-movement elevators could cater to new demographic profiles of occupants in large-scale, mixed-use vertical developments. An interdisciplinary team of researchers is required to fully examine how different floor layouts and creative geometries will impact different elevator solutions. Studies could examine different mixed-use schemes and vertical arrangements of different zones of the building. By involving traffic simulation and energy consumption modeling for various spatial arrangements and work schedules, the interdisciplinary team may arrive at more effective solutions for vertical urbanism. In the same manner, urban design research may assess and study the optimal arrangement of tall and super-tall buildings in the light of new elevator technological advancements. Studies could also compare the efficiencies and environmental impact of embracing more vertical transportation versus "horizontal” transportation, leading to "greener" spatial layout.

Jeff Mash and colleagues explain that proper planning of the vertical transportation system is critical in ensuring a successful community atmosphere in the vertical city. The planning team must fully understand the various demands the building will experience, driven by the wide-range of uses of a mixed-use skyscraper. Proper planning can make logistic operations more transparent to the public, tenants, and residents. The best logistics operations are those that run smoothly and without being noticed ([62], p. 865). If “smart” design teams are engaged to examine advanced elevator technologies, it may result in "greener" architecture for skyscrapers. An early collaboration between elevator's manufactures, developers, architects, urban designers, interior designers, and computer scientists may provide effective solutions that further reduce costs, improve performance, and promote efficiencies.

\section{Conflicts of Interest}

The authors declare no conflict of interest.

\section{References}

1. Wood, A. 2014 Best Tall Buildings. In Proceedings of the CTBUH Award Ceremony, 2 November 2014; Illinois Institute of Technology (IIT): Chicago, IL, USA. 
2. Neyfakh, L. How the Elevator Transformed America. The Boston Globe. 2014. Available online: https://www.bostonglobe.com/ideas/2014/03/02/how-elevator-transformed-america/b8u17Vx897 wUQ8zWMTSvYO/story.html (accessed on 1 June 2015).

3. Wilk, D. Tales from the Elevator and Other Stories of Modern Service in New York City. Enterp. Soc. 2006, 7, 690-704.

4. Bernard, A. Lifted: A Cultural History of Elevators; NYU Press: New York, NY, USA, 2014.

5. Gill, G. A Tall, Green Future. Struct. Des. Tall Spec. Build. 2008, 17, 857-868.

6. Gane, V.; Haymaker, J. Benchmarking Conceptual High-Rise Design Processes. J. Arch. Eng. 2010, 16, doi:10.1061/(ASCE)AE.1943-5568.0000017.

7. Chakraborty, A. Rethinking the role of service cores as a passive design tool in optimizing operational energy of tall buildings. Struct. Des. Tall Spec. Build. 2008, 17, 862-876.

8. Oldfield, P.; Trabucco, D.; Wood, A. Five Generations of Tall Buildings: An Historical Analysis of Energy Consumption in High Rise Buildings. J. Arch. 2009, 14, 591-610.

9. Ali, M.M.; Armstrong, P.J. Overview of Sustainable Design Factors in High-Rise Buildings. In Proceedings of the CTBUH World Congress, Dubai, United Arab Emirates, 22-24 March 2008.

10. Sachs, H.M.; Russell, C.; Rogers, E.; Nadel, S. Depreciation: Impacts of Tax Policy; ACEEE: Washington, DC, USA, 2012.

11. Frontmatter. In The Vertical Transportation Handbook, 4th ed.; Strakosch, G.R., Caporale, R.S., Eds.; John Wiley \& Sons, Inc.: Hoboken, NJ, USA. 2010.

12. Hutt, B.; Butcher, K.; Rowe, J. Energy Efficiency in Buildings; CIBSE Guide F. 2nd ed, 2004. Available online: http://www.notionparallax.co.uk/wordpress/wp-content/uploads/2011/03/ CIBSE-GUIDE-F-ENERGY-EFFICIENCY-IN-BUILDINGS-2004-.pdf (accessed on 10 September 2015).

13. Bos, J.; Wei, C.S.; Dell, R.; Foley, W. Developing a Methodology for Measuring the Comparative Energy Efficiency of Elevators. In Proceedings of the Presentation at the ASME International Mechanical Engineering Congress and Exposition (IMECE), San Diego, CA, USA, 15-21 November 2013; ASME: New York, NY, USA.

14. Gifford, H. Elevator Energy Use. Home Energy Magazine, 12 February 2010.

15. Enermodal Engineering. Market Assessment for Energy Efficient Elevators and Escalators; Enermodal Engineering: Kitchener, Canada, 2004.

16. Gilleo, A.; Chittum, A.; Farley, K.; Neubauer, M.; Nowak, S.; Ribeiro, D.; Vaidyanathan, S. The 2014 State Energy Efficiency Scorecard; ACEEE: Washington, DC, USA, 2014.

17. Al-Kodmany, K. Eco-Towers: Sustainable Cities in the Sky; WIT Press: Southampton, UK, 2015.

18. Al-Kodmany, K.; Ali, M. The Future of the City: Tall Buildings and Urban Design; WIT Press: Southampton, UK, 2012.

19. Nemeth, B. Energy-Efficient Elevator Machines; ThyssenKrupp Elevator: Frisco, TX, USA, 2011.

20. Pederick, G. How Vertical Transportation is Helping Transform Modern City; CTBUH: Chicago, IL, USA, 2014; pp. 853-860.

21. Kwatra, S.; Essig, C. The Promise and the Potential of Comprehensive Commercial Building Retrofit Programs; ACEEE: Washington, DC, USA, 2014.

22. Bass, P. Energy Efficient Elevator Solutions for High-Rise Buildings; CTBUH: Chicago, IL, USA, 2014; pp. 830-833. 
23. De Almeida, A.; Hirzel, S.; Patrão, C. Fong, J.; Dütschke, E. Energy-Efficient Elevators and Escalators in Europe: An Analysis of Energy Efficiency Potentials and Policy Measures. Energy Build. 2012, 47, 151-158.

24. Kroll, K. How to Reduce Elevators' Energy Use. Available online: http://www.facilitiesnet. com/elevators/article/How-To-Reduce-Elevators-Energy-Use-Facilities-Management-ElevatorsFeature--15510 (accessed on 15 December 2014).

25. Sachs, H.; Misuriello, H.; Kwatra, S. Advancing Elevator Energy Efficiency; American Council for an Energy-Efficient Economy: Washington, DC, USA, 2015.

26. Snyder, L. Elevators Moving up on Energy Efficiency. Facilitiesnet. Available online: http://www.facilitiesnet.com/elevators/article/Elevators-Moving-Up-On-Energy-EfficiencyFacilities-Management-Elevators-Feature--7549 (accessed on 12 October 2007).

27. Hughes, J.V. Regenerative Elevator Drives May Save Energy-And Dollars. Available online: http://www.habitatmag.com/Publication-Content/2010/2010-June/Featured-Articles-from-OurPrint-Magazine/Regenerative-Elevator-Drives\#.VXxjsvlViko (accessed on 21 June 2010).

28. De Jong, J. Advances in Elevator Technology: Sustainable and Energy Implications; CTBUH: Chicago, IL, USA, 2008; pp. 1-7.

29. De Jong, J. Innovative Elevator Technologies to Future Proof Your Building; CTBUH: Chicago, IL, USA, 2014; pp. 817-823.

30. KONE. New KONE UltraRope(TM) Elevator Hoisting Technology Enables the Next Big Leap in High-Rise Building Design. Available online: http://www.kone.com/en/press/press/new-koneultrarope-tm-elevator-hoistingtechnology-enables-the-next-big-leap-in high-rise-building-design2013-06-10.aspx (accessed on 1 June 2015).

31. Carbon Fiber Rope Is the Next Big Leap in High-Rise Building Design. High-Rise Facilities. Available online: http:// highrisefacilities.com/carbon-fiberrope-is-the-next-big-leap-in-highrisebuilding-design/ (accessed on 1 June 2015).

32. CTBUH and BD $+\mathrm{C}$ Staff. 5 Innovations in High-Rise Building Design. Building Design + Construction. Available online: http://www.bdcnet work.com/5-innovations-high-rise-buildingdesign (accessed on 1 June 2015).

33. KONE. KONE Awarded CTBUH's 2013 Innovation Award for KONE UltraRope. Available online: http://www.ctbuh.org/LinkClick.aspx?fileticket=p\%2B2K401tzS8\%3D\&tabid=62\&language=en-US (accessed on 1 June 2015).

34. Sniderman, D. Energy Efficient Elevator. Technologies; ASME, September 2012. Available online: https://www.asme.org/engineering-topics/articles/elevators/energy-efficient-elevator-technologies (accessed on 5 September 2015)

35. Lau, T. Power, Elevator and Customer-Oriented Sustainability Strategies; CTBUH: Chicago, IL, USA, 2014; pp. 84-93.

36. Klan, G.; Edgett, S.; Armas, J. Advancements in Tall Building Vertical Transportation Design; CTBUH: Chicago, IL, USA, 2012; pp. 594-600.

37. Rosman, K. The Most Awkward Meeting; New Elevators Sort Employees, Foiling Manners and Face Time. The Wall Street J. 2011, 17, 22-28.

38. Boog, R. Green Vertical Transportation: More than Just a Concept; CTBUH: Chicago, IL, USA, 2014. pp. 812-816. 
39. ASHRAE. ANSI/ASHRAE/IES/USGBC Standard 189.1-2014, Standard for the Design of High-Performance Green Buildings; ASHRAE: Atlanta, GA, USA, 2014.

40. Fortune, J. Elevator Destination Dispatching: A Revolution in Making; CTBUH: Chicago, IL, USA, 2012; pp. 601-606.

41. Al-Kodmany, K. Sustainable Tall Buildings: Toward a Comprehensive Design Approach. Int. J. Sustain. Des. 2012, 2, 1-23.

42. Klote, J. Elevator Pressurization in Tal Buildings. Int. J. High Rise Build. 2013, 2, 341-344.

43. Smart Technology Improves Elevator Maintenance. Nationwide Lifts. Available online: http://www.elevatordesigninfo.com/smart-technology-improves-elevator-maintenance (accessed on 1 June 2015).

44. Mosbergen, D. Elevator Journey to the Top of 1 World Trade Center Features Spectacular Time-Lapse History of New York. The Huffington Post. Available online: http://www.huffingtonpost.com/ 2015/04/20/elevator-one-world-trade-center-time-lapse_n_7105280.html (accessed on 1 June 2015).

45. One World Trade Center Elevators Offer 500-Year History Ride-In 47 s. The New York Times. Available online: http:/www.theguardian.com/us-news/2015/apr/20/one-world-trade-centerelevators-500- (accessed on 1 June 2015).

46. Abrams, M. Race to the Top. ASME. Available online: https://www.asme.org/engineeringtopics/articles/elevators/race-to-the-top (accessed on 1 June 2015).

47. Burj Dubai Features World's Highest Elevators. WORLD. Available online: http://news.xinhuanet. com/english/2010-01/04/content_12753604.htm (accessed on 1 April 2010).

48. Lowe, A.; Saleem, N. "Evacuation during Emergency Will Be a Smooth Process in Burj Khalifa" Gulf New. Available online: http://gulfnews.com/business/property/evacuation-during-emergencywill-be-a-smooth-process-in-burj-khalifa-1.562336 (accessed on 5 January 2010).

49. Beyer, M.T. An Evaluation of the Fire and Wind Safety of the Burj Dubai; University of Wisconsin-Madison, Mechanical Engineering: Madison, WI, USA, 2009.

50. CW Staff. How the Burj Khalifa Was Built UPDATED, Construction Week Online. Available online: http://www.constructionweekonline.com/article-32805-how-the-burj-khalifa-was-builtupdated/5/ (accessed on 3 March 2015).

51. Weismantale, P. Case Study: Kingdom Tower, Jeddah; CTBUH: Chicago, IL, USA, 2013; pp. 12-19.

52. Borgobello, B. Tower Infinity "Invisible” Skyscraper Receives Go-Ahead. Gizmag. Available online: http://www.gizmag.com/tower-infinity-invisibleskyscraper-gds-architects/29061/ (accessed on 23 September 2013); (retrieved 1 June 2015).

53. Gordon, J. Dubai Skyscraper Is One Giant Wind and Solar Generator. Tree Hugger. Available online: http://www.treehugger.com/sustainable-productdesign/dubai-skyscraper-is-one-giantwind-andsolar-generator.html (accessed on 11 March 2010); (retrieved 1 June 2015).

54. Personeni, M. Door Technology for High-Rise Applicants; CTBUH: Chicago, IL, USA, 2014; pp. 874-878.

55. Wall, M. Japanese Company Aims for Space Elevator by 2050. Available online: http://www.space.com/14656-jap anese-space-elevator-2050-proposal.html (accessed on 23 February 2012); (retrieved 1 June 2015). 
56. Wood, A.; Baitz, C. Maglev Goes High Rise? The Potential of Maglev Technology for Vertical High-Rise Elevators. CTBUH J. 2007, 26-29.

57. Going “Green” in Elevator and Escalator Design. Available online: http://www.schindler.com/ content/us/internet/en/about-us/sustainability/leed/_jcr_content/rightPar/downloadlist/download List/58_1337193702705.download.asset.58_1337193702705/goinggreenwhitepaper5-27-10.pdf (accessed on 15 June 2015).

58. Barney, G. Towards Low Carbon Lifts; Gina Barney Associates: London, UK, 2006.

59. Al-Kodmany, K. Green Retrofitting Skyscrapers: A Review. Buildings 2014, 4, 683-710.

60. Al-Kodmany, K. Green Towers: Toward Sustainable and Iconic Design. Int. J. Arch. Plan. Res. 2014, 8, 11-28.

61. Mizon, J. Transit Care, an Opportunity for Multi-Function Tall Buildings; CTBUH: Chicago, IL, USA, 2012; pp. 250-254.

62. March, J.; Rupe, E.; Baker, R. Vertical Transportation and Logistics in Mixed-Use High-Rise Towers; CTBUH: Chicago, IL, USA, 2014; pp. 861-865.

(C) 2015 by the authors; licensee MDPI, Basel, Switzerland. This article is an open access article distributed under the terms and conditions of the Creative Commons Attribution license (http://creativecommons.org/licenses/by/4.0/). 